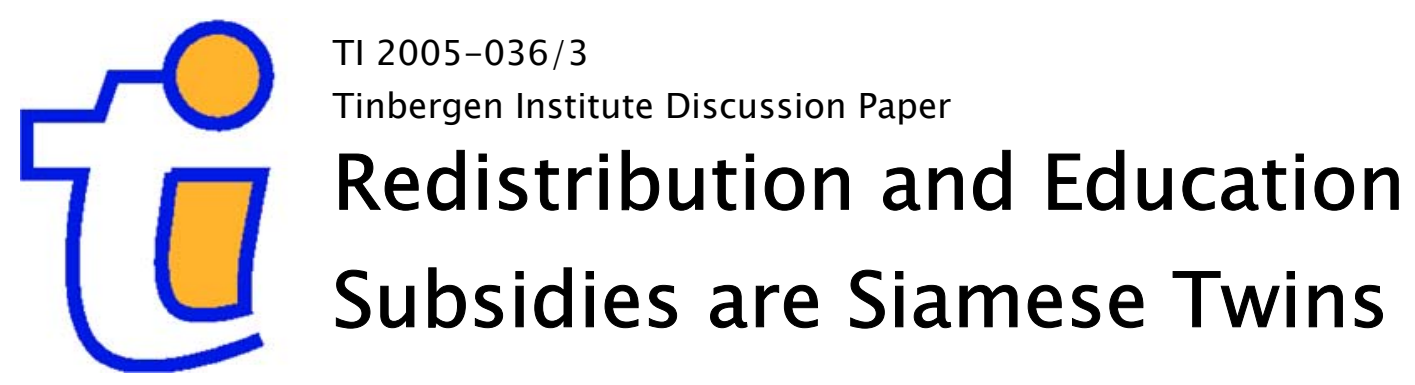

\author{
A. Lans Bovenberg \\ Bas Jacobs
}

${ }^{1}$ CentER, Tilburg University, Erasmus Universiteit Rotterdam, and CEPR.

2 University of Amsterdam, CPB Netherlands Bureau for Economic Policy Analysis, and Tinbergen Institute. 


\section{Tinbergen Institute}

The Tinbergen Institute is the institute for economic research of the Erasmus Universiteit Rotterdam, Universiteit van Amsterdam, and Vrije Universiteit Amsterdam.

Tinbergen Institute Amsterdam

Roetersstraat 31

1018 WB Amsterdam

The Netherlands

Tel.: $\quad+31(0) 205513500$

Fax: $\quad+31(0) 205513555$

Tinbergen Institute Rotterdam

Burg. Oudlaan 50

3062 PA Rotterdam

The Netherlands

Tel.: $\quad+31(0) 104088900$

Fax: $\quad+31(0) 104089031$

Please send questions and/or remarks of nonscientific nature to driessen@tinbergen.nl.

Most TI discussion papers can be downloaded at http://www.tinbergen.nl. 


\title{
Redistribution and Education Subsidies are Siamese Twins*
}

\author{
A. Lans Bovenberg ${ }^{\dagger \diamond}$ and Bas Jacobs ${ }^{\ddagger}$ \\ Working Paper - September, 2003
}

\begin{abstract}
We develop a model of human capital formation with endogenous labor supply and heterogeneous agents to explore the optimal level of education subsidies along with the optimal schedule of the labor income tax. If the government can observe inputs into the production of human capital, subsidies on education ensure efficiency in human capital accumulation and labor taxes are more progressive than without education policies. Although the able benefit more than proportionally from education subsidies, education subsidies thus play an important role in alleviating the tax distortions in human capital accumulation induced by redistributive policies. If the government can not verify all investments in human capital, education policy offsets some but not all the tax-induced distortions on learning.
\end{abstract}

Keywords: human capital, education subsidies, progressive taxation, redistribution.

JEL codes: H2, H5, I2, J2.

* Bas Jacobs gratefully acknowledges financial support from the NWO Priority Program 'Scholar' funded by the Netherlands Organization for Sciences.

†Tilburg University, CentER, Erasmus University, OCfEB, and CEPR. E-mail: a.l.bovenberg@uvt.nl. ‡University of Amsterdam, and CPB Netherlands Bureau for Economic Policy Analysis. E-mail: b.jacobs@uva.nl. ${ }^{\circledR}$ Corresponding author: CentER, Tilburg University, P.O. Box 90153, 5000 LE Tilburg, The Netherlands. Phone: $(+31)-$ 13 - 466 2912. Fax: (+31) - 13 - 4663066. 


\section{Introduction}

Most OECD countries heavily subsidize higher education. These education subsidies are typically justified on the basis of perceived positive external effects of human capital accumulation, capital market imperfections, and redistributional concerns. Positive external effects of higher education, however, are difficult to establish empirically (see, e.g., Heckman and Klenow, 1998; Acemoglu and Angrist, 2000; Krueger and Lindahl, 2002). Also capital market imperfections do not seem to be very important in practice (see, e.g., Shea, 2000; Cameron and Taber, 2000; and Carneiro and Heckman, 2003). ${ }^{1}$ Education subsidies, morover, typically transfer resources away from unskilled towards skilled, educated individuals so that their distributional effects appear perverse. ${ }^{2}$ Why, then, is education subsidized?

We provide a second-best case for education subsidies on the basis of redistributional considerations rather than externalities and capital market imperfections. Although the able benefit more than proportionally from education subsidies, we show that education subsidies play an important role in alleviating the tax distortions in human capital accumulation induced by redistributive policies. ${ }^{3}$ This explains why OECD countries subsidize higher education more heavily if the income tax is more progressive (see Figure 1).

Our paper explores the interaction between public spending and tax policies by viewing education subsidies and tax policies as interdependent instruments aimed at redistribution. ${ }^{4}$ We add endogenous human capital formation

\footnotetext{
${ }^{1}$ In any case, loans rather than subsidies are the most direct way to address liquidity constraints (see Jacobs and van Wijnbergen (2002)).

${ }^{2}$ Dur and Teulings (2001), however, argue that education subsidies benefit unskilled individuals by boosting the supply of skilled workers compared to that of unskilled workers, thereby reducing wage differentials between skilled and unskilled workers. For realistic parameter values, they find that this general equilibrium effect broadly offsets the direct regressive impact of educational subsidies.

${ }^{3}$ Boadway et al. (1996) and Andersson and Konrad (2001) offer an alternative explanation for education subsidies. They argue that education subsidies are called for if the government cannot commit, and engages in excessive redistribution after investments in human capital have been made. We show that education subsidies are part of an optimal policy package - even if the government can commit to announced policies.

${ }^{4}$ The public finance literature on the effects of taxation on the incentives to accumulate human capital, in contrast, has typically abstracted from both public spending on education and distributional considerations, see e.g., Boskin (1975), Heckman (1976), Kotlikoff and Summers (1979), Eaton and Rosen (1980), Trostel (1993), Nielsen and Sørensen (1997), Milesi-Feretti and Roubini (1998), and Judd (1999).
} 
Figure 1: Marginal taxes and education subsidies in various OECD countries

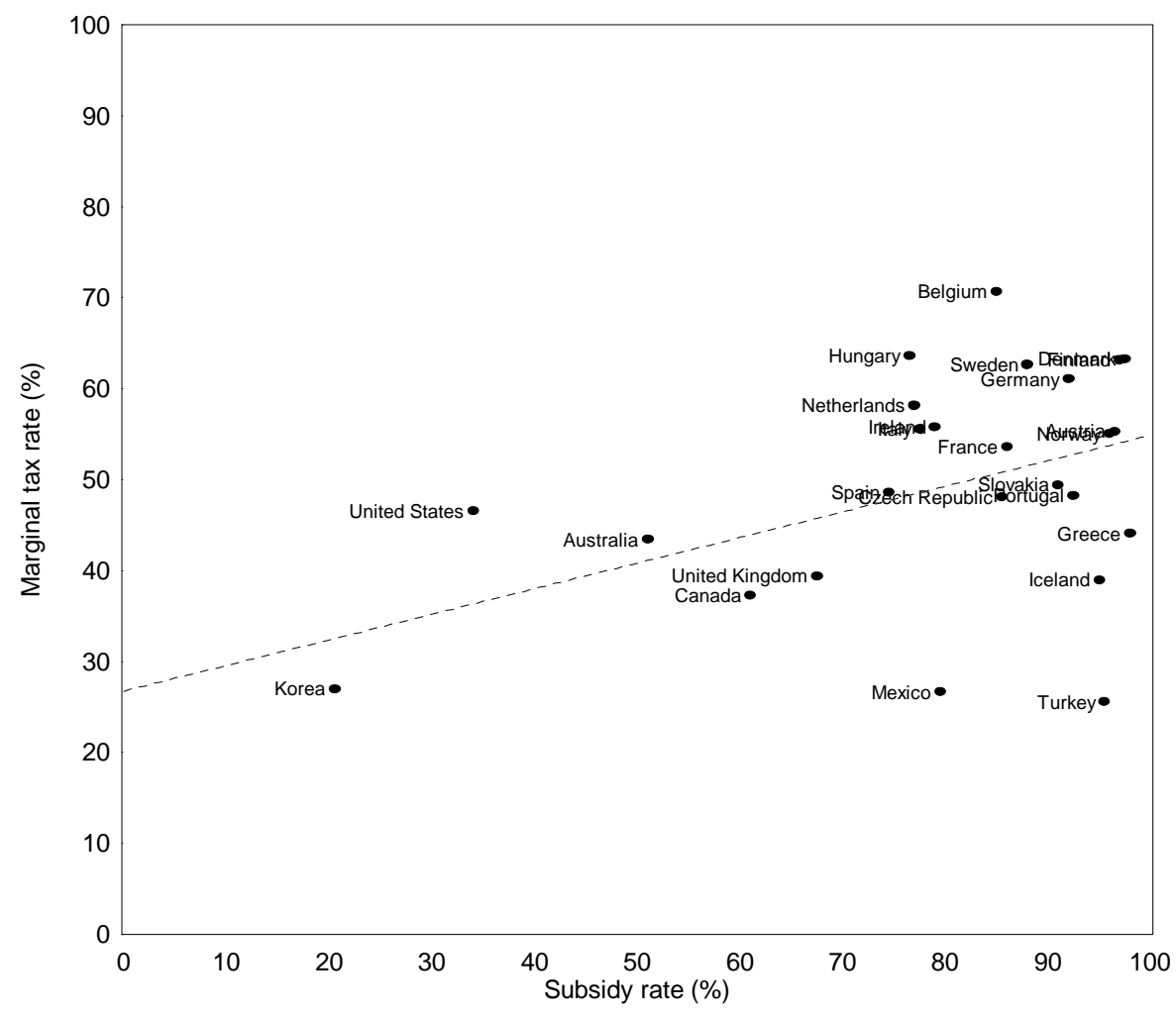

to the standard models of optimal income taxation and investigate how the availability of education subsidies affects the optimal income tax system. Our paper contributes in a number of ways to the optimal tax literature.

First, we derive the optimal income tax in the absence of education policies to show that optimal marginal income taxes are reduced below levels that would be optimal in the absence of endogenous human capital formation. Intuitively, the efficiency costs of redistribution increase, as positive marginal tax rates distort not only labor supply but also human capital accumulation.

Second, if the government has education subsidies at its disposal, the distortions of taxes on learning decisions are eliminated so as to restore efficiency in education choices. Indeed, education subsidies provide the government with sufficient instruments to restore efficiency in the production of human capital (see also Diamond and Mirrlees (1971)). By eliminating 
the distortions of redistribution on learning, education subsidies make the optimal labor tax more progressive than without education subsidies.

Third, if the income tax is not available, the government would want to tax - rather than subsidize - education. Hence, the availability of an income tax as a redistributional device justifies education subsidies. Intuitively, the income tax is better targeted at income redistribution because all income is taxed - including the rents from ability. An education tax, in contrast, extracts only the returns from human capital formation, which exclude the rents from ability.

We explore also whether these three contributions are robust with respect to the observability of learning and individual incomes. If the government can not verify all investments in human capital, it offsets some but not all the tax-induced distortions on human capital accumulation. Intuitively, whereas education subsidies help to alleviate the adverse impact of taxes on the level of aggregate learning, they also distort the composition of the inputs in human capital formation away from non-verifiable inputs. Furthermore, we show that the main results derived with linear policy instruments also hold if the government has access to a non-linear income tax and non-linear education subsidies, which require the government to observe individual incomes and individual learning efforts.

Our paper extends earlier work by Ulph (1977) and Hare and Ulph (1979). Also these papers explore optimal policy if both the income tax and education expenditures are simultaneously optimized. They assume, however, that the government can directly set the level of education. With agents not deciding on human capital formation themselves, taxation does not distort education decisions. This contrasts with our paper, in which income taxes distort individual decisions on human capital accumulation.

Our paper is related also to Lommerud (1989), and van Ewijk and Tang (2000). In Lommerud (1989), the government taxes labor income in order to internalize the negative externalities from status seeking, but employs education subsidies to restore incentives to undertake education. In van Ewijk and Tang (2000), the government employs progressive taxes to punish wage demands of unions and to raise employment, but this discourages learning efforts. Education subsidies allow the government to set progressive labor taxes without distorting human capital accumulation. Both papers, however, abstract from distributional concerns as the main reason for imposing progressive income taxes.

The rest of this paper is structured as follows. Section 2 describes the 
fundamental building blocks of our model: preferences and technologies. Section 3 explores optimal linear tax and linear education policies. Section 4 shows that the main results continue to hold if non-linear policy instruments would be available. Before section 6 concludes, section 5 discusses the policy implications of the analysis. The appendix contains the technical derivations of the results.

\section{Preferences and technologies}

Our model extends the standard model of optimal income taxation with endogenous earning potential through human capital formation. Individuals are heterogeneous with respect to their exogenous ability $n$. The cumulative distribution of ability is denoted by $F(n) . f(n)$ is the corresponding density function, which is continuously differentiable and strictly positive on the support $[\underline{n}, \bar{n}], \underline{n}, \bar{n}>0 .^{5}$ The government knows the distribution of abilities, but cannot observe individual ability. Accordingly, it cannot levy individual-specific lump-sum taxes to redistribute incomes, but must rely on distortionary taxes instead.

Individuals invest an amount $x_{n}$ of their resources on acquiring human capital. These resources are deductible from the income tax. $p_{x}$ denotes the unit cost of $x_{n}$. We can interpret $x_{n}$ as foregone labor time of an unskilled worker. With this interpretation, $p_{x}$ represents the wage rate of an unskilled worker. Individuals also invest $y_{n}$ units of non tax-deductible resources in education. These investments include books, computers and tuition. These costs cannot be deducted from the income tax because individuals typically earn no (or very low) labor incomes when they put these resources into education. The unit cost price of $y_{n}$ is $p_{y}$.

Ability $n$ is the productivity of inputs invested in education, so that more able individuals produce more human capital with the same inputs. The production function for human capital is homothetic in the two inputs $x_{n}$ and $y_{n}$ :

$$
h_{n}=n \phi\left(x_{n}, y_{n}\right) \equiv n\left(\psi\left(x_{n}, y_{n}\right)\right)^{\beta},
$$

where $h_{n}$ denotes human capital, and $\psi($.$) is a concave constant-returns-$ to-scale production function, with positive but diminishing returns to the inputs into education: $\psi_{x}, \psi_{y}>0, \psi_{x x}, \psi_{y y}<0, \psi_{x y}>0$. Human capital

\footnotetext{
${ }^{5}$ The upper bound $\bar{n}$ may be infinite.
} 
accumulation exhibits decreasing returns with respect to investment, i.e., $\beta<1$. Ability and educational investments are complementary inputs in generating human capital, i.e., $\frac{\partial^{2} h_{n}}{\partial x_{n} \partial n}=\beta\left(\psi\left(x_{n}, y_{n}\right)\right)^{\beta-1} \psi_{x} \geq 0, \frac{\partial^{2} h_{n}}{\partial y_{n} \partial n}=$ $\beta\left(\psi\left(x_{n}, y_{n}\right)\right)^{\beta-1} \psi_{y} \geq 0$. Gross labor income $z_{n}$ is the product of the number of efficiency units of human capital, $h_{n}$, and hours worked $l_{n}$, i.e., $z_{n} \equiv$ $h_{n} l_{n}=n \phi\left(x_{n}, y_{n}\right) l_{n}{ }^{6}$

Households feature a common, concave, and twice differentiable utility function, which is increasing in consumption $c_{n}$, and decreasing in work effort $l_{n}$

$$
u\left(c_{n}, l_{n}\right),
$$

with $u_{c}>0, u_{l}<0, u_{c c}<0, u_{l l}<0$.

\section{Linear tax and education policies}

This section derives the optimal linear income tax and education subsidies. Under a linear income tax, the government cannot observe individual gross labor incomes $z_{n}$, but only aggregate incomes $\int_{n}^{\bar{n}} z_{n} d F(n)$. The linear income tax consists of an impersonal marginal tax rate, $t$, and a non-individualized lump-sum transfer or poll subsidy $g$. If $y_{n}$ is verifiable, the government can subsidize these resources at rate $s_{y}$. In addition, $x_{n}$ may be subsidized at rate $s_{x}$, where after-subsidy education expenses on $x_{n}$ are deductible from the income tax.

\footnotetext{
${ }^{6}$ In this interpretation, the wage rate per efficiency unit of labor is normalized at unity. Alternatively, defining $\phi\left(x_{n}, y_{n}\right)$ (instead of $n \phi\left(x_{n}, y_{n}\right)$ ) as the efficiency units of labor (or human capital) per hour worked, we can interpret ability $n$ as the wage rate per efficiency unit of labor.
} 


\subsection{Individual optimization}

With this tax and subsidy code, the household budget constraint is ${ }^{7}$

$$
c_{n}=(1-t)\left(n \phi\left(x_{n}, y_{n}\right) l_{n}-\left(1-s_{x}\right) p_{x} x_{n}\right)-\left(1-s_{y}\right) p_{y} y_{n}+g
$$

Taking the policy instruments of the government as given, ${ }^{8}$ individuals maximize utility by choosing $c_{n}, l_{n}, x_{n}$ and $y_{n}$, subject to the household budget constraint. This yields the first-order conditions for the optimal choices of $x_{n}$ and $y_{n}$

$$
\begin{aligned}
n l_{n} \phi_{x} & =n l_{n} \beta\left(\psi\left(x_{n}, y_{n}\right)\right)^{\beta-1} \psi_{x}=\left(1-s_{x}\right) p_{x} \\
(1-t) n l_{n} \phi_{y} & =(1-t) n l_{n} \beta\left(\psi\left(x_{n}, y_{n}\right)\right)^{\beta-1} \psi_{y}=\left(1-s_{y}\right) p_{y} .
\end{aligned}
$$

Marginal benefits of investing a unit of resources should equal marginal costs. The marginal tax rate $t$ does not distort the $x$-margin, whereas it does distort the $y$-margin. Indeed, since $x_{n}$ is tax deductible, the tax rate $t$ equally affects the marginal benefits and the marginal costs of investing $x_{n}$. With the nondeductible input $y_{n}$, in contrast, taxes reduce only marginal benefits and do not affect costs, thereby distorting the optimal investment of $y_{n}$.

The first-order conditions for $x_{n}(4)$ and $y_{n}(5)$, and the production function of human capital (1) imply that gross labor income $z_{n}$ is proportional to both $x_{n}$ and $y_{n}$ :

$$
\begin{gathered}
z_{n}=n l_{n} \phi\left(x_{n}, y_{n}\right)=\frac{\left(1-s_{x}\right) p_{x}}{\alpha \beta} x_{n}, \\
z_{n}=n l_{n} \phi\left(x_{n}, y_{n}\right)=\frac{\left(1-s_{y}\right) p_{y}}{(1-\alpha) \beta(1-t)} y_{n} .
\end{gathered}
$$

\footnotetext{
${ }^{7}$ If we interpret $(1-t) p_{x} x_{n}$ as the taxed foregone earnings of an unskilled worker, we may add a (net) endowment of unskilled labor, $(1-t) p_{x}$, to the household budget constraint where we normalized the endowment of unskilled labor time to unity. $x_{n}$ then denotes the fraction of unskilled labor time invested in education. The additional term in the budget constraint, $(1-t) p_{x}$, implies that changes in $t$ give rise to additional income effects. As long as the government can optimally set $g$, however, these additional income effects do not affect any of the main results derived below. For notational convenience, we therefore abstract from this additional term in the household budget constraint.

${ }^{8}$ Indeed, the government sets policy before agents determine their behavior. In view of its distributional preferences, the government faces an incentive to renege on its promises after the private sector has accumulated human and financial capital. We thus have to assume that the government has access to a commitment technology (e.g., due to reputational considerations).
} 
With linear policy instruments, the proportionality factors do not depend on ability $n$, because the shares of $x_{n}$ and $y_{n}$ in human capital investment, $\alpha \equiv$ $\frac{x_{n} \psi_{x}}{\psi}=\frac{(1-t)\left(1-s_{x}\right) p_{x} x_{n}}{(1-t)\left(1-s_{x}\right) p_{x} x_{n}+\left(1-s_{y}\right) p_{y} y_{n}}$ and $1-\alpha \equiv \frac{y_{n} \psi_{y}}{\psi}=\frac{\left(1-s_{y}\right) p_{y} y_{n}}{(1-t)\left(1-s_{x}\right) p_{x} x_{n}+\left(1-s_{y}\right) p_{y} y_{n}}$, are the same for all agents (see appendix).

The first-order condition for labor supply amounts to

$$
\frac{-u_{l}}{u_{c}}=(1-t) n \phi\left(x_{n}, y_{n}\right)=(1-t) n\left(\psi\left(x_{n}, y_{n}\right)\right)^{\beta}
$$

The second-order conditions for a maximum imply (see appendix)

$$
\mu_{n} \equiv 1-\beta\left(1+\varepsilon_{n}\right)>0
$$

where $\varepsilon_{n} \equiv \frac{\partial l_{n}^{*}}{\partial w_{n}} \frac{w_{n}}{l_{n}^{*}}$, denotes the compensated after-tax wage elasticity of labor supply, $w_{n} \equiv(1-t) n \phi\left(x_{n}, y_{n}\right)$, and asterisks stand for compensated changes. The positive feedback between human capital and labor supply implies that decreasing returns in the production of human capital $(\beta<1)$ are not sufficient for the second-order condition to be met. In particular, more learning raises compensated labor supply, which in turn makes learning more attractive. This positive feedback effect, which depends on the compensated wage elasticity of labor supply $\varepsilon_{n}$, should be offset by sufficiently strong decreasing returns in learning to prevent corner solutions.

Totally differentiating the first-order conditions for $x_{n}$ and $y_{n}((4)$ and (5)) and the compensated labor supply function $l_{n}^{*}\left(w_{n}\right)$ yields the following compensated elasticities of the endogenous variables with respect to the policy parameters (see appendix):

$$
\begin{gathered}
\varepsilon_{l t} \equiv \frac{\partial l_{n}^{*}}{\partial t} \frac{(1-t)}{l_{n}^{*}}=-\frac{\varepsilon_{n}(1-\alpha \beta)}{\mu_{n}} \leq 0 \\
\varepsilon_{l s_{x}} \equiv \frac{\partial l_{n}^{*}}{\partial s_{x}} \frac{\left(1-s_{x}\right)}{l_{n}^{*}}=\frac{\varepsilon_{n} \alpha \beta}{\mu_{n}} \geq 0 \\
\varepsilon_{l s_{y}} \equiv \frac{\partial l_{n}^{*}}{\partial s_{y}} \frac{\left(1-s_{y}\right)}{l_{n}^{*}}=\frac{\varepsilon_{n}(1-\alpha) \beta}{\mu_{n}} \geq 0 \\
\varepsilon_{x t} \equiv \frac{\partial x_{n}^{*}}{\partial t} \frac{(1-t)}{x_{n}^{*}}=-\frac{\varepsilon_{n}+(1-\alpha) \beta\left(1+\varepsilon_{n}\right)}{\mu_{n}}+(1-\alpha)(\sigma-1) \lessgtr 0 \\
\varepsilon_{x s_{x}} \equiv \frac{\partial x_{n}^{*}}{\partial s_{x}} \frac{\left(1-s_{x}\right)}{x_{n}^{*}}=\frac{1-(1-\alpha) \beta\left(1+\varepsilon_{n}\right)}{\mu_{n}}+(1-\alpha)(\sigma-1) \geq 0
\end{gathered}
$$




$$
\begin{gathered}
\varepsilon_{x s_{y}} \equiv \frac{\partial x_{n}^{*}}{\partial s_{y}} \frac{\left(1-s_{y}\right)}{x_{n}^{*}}=\frac{(1-\alpha) \beta\left(1+\varepsilon_{n}\right)}{\mu_{n}}-(1-\alpha)(\sigma-1) \lessgtr 0, \\
\varepsilon_{y t} \equiv \frac{\partial y_{n}^{*}}{\partial t} \frac{(1-t)}{y_{n}^{*}}=-\frac{(1-\alpha \beta)\left(1+\varepsilon_{n}\right)}{\mu_{n}}-\alpha(\sigma-1) \leq 0, \\
\varepsilon_{y s_{x}} \equiv \frac{\partial y_{n}^{*}}{\partial s_{x}} \frac{\left(1-s_{x}\right)}{y_{n}^{*}}=\frac{\alpha \beta\left(1+\varepsilon_{n}\right)}{\mu_{n}}-\alpha(\sigma-1) \lessgtr 0, \\
\varepsilon_{y s_{y}} \equiv \frac{\partial y_{n}^{*}}{\partial s_{y}} \frac{\left(1-s_{y}\right)}{y_{n}^{*}}=\frac{1-\alpha \beta\left(1+\varepsilon_{n}\right)}{\mu_{n}}+\alpha(\sigma-1) \geq 0,
\end{gathered}
$$

where $\sigma \equiv-\frac{d\left(x_{n} / y_{n}\right)}{d\left(\psi_{x} / \psi_{y}\right)}$ denotes the elasticity of substitution between the two inputs in the production function for human capital. ${ }^{9}$

A larger marginal tax rate $t$ affects private decisions through three channels: reducing labor supply (if $\varepsilon_{n}>0$ ), depressing aggregate learning efforts (if $\alpha<1$, so that some inputs are not tax deductible), and substituting tax-deductible for non tax-deductible resources in the production of human capital. The education subsidies $s_{x}$ and $s_{y}$ affect investment decisions in human capital at the aggregate level and through the composition of inputs into human capital formation. In some cases, policy effects cannot be signed because the impact on aggregate learning has the opposite sign of the corresponding effect on the composition of learning. To illustrate, depending on the substitution elasticity $\sigma$, the negative aggregate learning effect of a higher tax rate on $x_{n}$ may offset a positive substitution effect, as tax deductible inputs are substituted for inputs that are not tax deductible.

\subsection{Government}

The government collects taxes to finance exogenously given expenditures, $E$, the education subsidies $s_{x}$ and $s_{y}$, and the uniform lump-sum transfer $g$. The government budget constraint therefore reads as

$$
\begin{aligned}
& t \int_{\underline{n}}^{\bar{n}}\left(n \phi\left(x_{n}, y_{n}\right) l_{n}-\left(1-s_{x}\right) p_{x} x_{n}\right) d F(n) \\
= & \int_{\underline{n}}^{\bar{n}}\left(s_{x} p_{x} x_{n}+s_{y} p_{y} y_{n}+g+E\right) d F(n) .
\end{aligned}
$$

\footnotetext{
${ }^{9}$ The appendix shows that homotheticity of $\psi\left(x_{n}, y_{n}\right)$ implies that not only $\alpha$ but also $\sigma$ is independent of ability.
} 
We can write the indirect utility function as a function of the policy parameters: $v\left(g, t, s_{x}, s_{y}, n\right)$. The government maximizes a social welfare function defined over individuals' indirect utilities $\Gamma$

$$
\Gamma=\int_{\underline{n}}^{\bar{n}} \Psi\left(v\left(g, t, s_{x}, s_{y}, n\right)\right) d F(n),
$$

where $\Psi^{\prime}>0$, and $\Psi^{\prime \prime} \leq 0$. With $\Psi^{\prime}=1$, the social welfare function is utilitarian (see Atkinson and Stiglitz (1980)).

The Lagrangian for maximizing social welfare is given by

$$
\begin{aligned}
& \max _{\left\{g, t, s_{x}, s_{y}\right\}} \mathcal{L}=\int_{\underline{n}}^{\bar{n}} \Psi\left(v\left(g, t, s_{x}, s_{y}, n\right)\right) d F(n) \\
& +\lambda \int_{\underline{n}}^{\bar{n}}\left(t\left(n \phi\left(x_{n}, y_{n}\right) l_{n}-\left(1-s_{x}\right) p_{x} x_{n}\right)-s_{y} p_{y} y_{n}-s_{x} p_{x} x_{n}-g-E\right) d F(n),
\end{aligned}
$$

where $\lambda$ is the Lagrange multiplier of the government budget constraint.

\subsection{Optimal lump-sum transfer}

The first-order condition for maximizing the Lagrangian (21) with respect to the lump-sum transfer $g$ amounts to

$$
\frac{\partial \mathcal{L}}{\partial g}=\int_{\underline{n}}^{\bar{n}}\left(\Psi^{\prime} \eta_{n}-\lambda+\lambda \operatorname{tn} \phi(.) \frac{\partial l_{n}}{\partial g}+\lambda \Delta_{x} \frac{\partial x_{n}}{\partial g}+\lambda \Delta_{y} \frac{\partial y_{n}}{\partial g}\right) d F(n)=0,
$$

where we used Roy's lemma, and $\eta_{n}$ denotes the private marginal utility of income of individual with ability $n . \Delta_{x}$ and $\Delta_{y}$ represent the tax wedges on the two inputs into human capital accumulation; i.e., $\Delta_{x} \equiv$ $t\left(n \phi_{x}(.) l_{n}-\left(1-s_{x}\right) p_{x}\right)-s_{x} p_{x}=-s_{x} p_{x}$ (from the first-order condition for $\left.x_{n}(4)\right)$ and $\Delta_{y} \equiv \operatorname{tn} \phi_{y}(.) l_{n}-s_{y} p_{y}=\frac{\left(t-s_{y}\right) p_{y}}{1-t}$ (from the first-order condition for $\left.y_{n}(5)\right)$.

By defining the net social marginal value of income of an $n$-man (including the effect on the tax base)

$$
b_{n} \equiv \frac{\Psi^{\prime} \eta_{n}}{\lambda}+\operatorname{tn} \phi\left(x_{n}, y_{n}\right) \frac{\partial l_{n}}{\partial g}+\Delta_{x} \frac{\partial x_{n}}{\partial g}+\Delta_{y} \frac{\partial y_{n}}{\partial g},
$$

we can write the first-order condition for $g(22)$ as

$$
\bar{b} \equiv \int_{\underline{n}}^{\bar{n}} b_{n} d F(n)=1
$$


The average social marginal benefits of a higher $g$ (i.e., the left-hand side of (24)) should equal the costs in terms of a higher $g$ (i.e., the right-hand side of $(24))$.

With the aid of the first-order condition for $g(24)$, we define the so-called distributional characteristic $\xi$ of labor income as

$$
\xi \equiv \frac{\int_{\underline{n}}^{\bar{n}}\left(1-b_{n}\right) z_{n} d F(n)}{\int_{\underline{n}}^{\bar{n}} z_{n} d F(n)} .
$$

$\xi$ is the negative normalized covariance between the welfare weight the government attaches to income of a particular ability $b_{n}$ and gross labor income $z_{n}$ (see, e.g., Atkinson and Stiglitz (1980)). This covariance coincides with the normalized covariances of the welfare weights with both inputs in learning $\left(x_{n}\right.$ and $\left.y_{n}\right)$ and the base of the income tax $\left(z_{n}-\left(1-s_{x}\right) p_{x} x_{n}\right)$, because labor income $z_{n}$ is proportional to investments in education $x_{n}$ and $y_{n}$ (see (6) and (7)). A positive distributional characteristic $\xi$ thus implies that the income tax base is larger for high-ability agents (who feature relatively low welfare weights) than for low-ability agents (who feature relatively high welfare weights), so that taxing labor income yields distributional benefits. The magnitude of the distributional characteristic depends not only on the correlation between ability and the tax base, but also on the correlation between ability and the welfare weights. ${ }^{10}$ Indeed, a zero distributional characteristic implies either that the government is not interested in redistribution (so that the welfare weight is the same for all $n$ ) or that the marginal contribution to the tax base is equal for all ability types (taxable income is the same for all $n)$.

\subsection{Optimal income taxation}

This section derives the optimal linear income tax in the absence of education policy $\left(s_{x}=s_{y}=\Delta_{x}=0\right.$ and $\left.\Delta_{y}=\frac{t p_{y}}{1-t}\right)$. The optimal linear income tax follows from taking the first-order condition for maximizing the Lagrangian

\footnotetext{
${ }^{10}$ The strength of this negative correlation depends both on the concavity of the function $\Psi$ and on inequality in utility levels. In particular, the government attaches a higher priority to redistributing incomes if more unequal utility levels produce larger differences in marginal utilities of income $\eta_{n}$ and thus $b_{n}$.
} 
(21) with respect to $t$ and substituting the distributional characteristic (25):

$$
\frac{t}{1-t}=\frac{\xi(1-\alpha \beta)}{-\bar{\varepsilon}_{l t}-(1-\alpha) \beta \bar{\varepsilon}_{y t}} .
$$

Here, and in the rest of the paper, upper bars denote income-weighted elasticities (i.e., $\bar{\epsilon} \equiv \frac{\int_{n}^{\bar{n}} \epsilon z_{n} d F(n)}{\int_{n}^{\bar{n}} z_{n} d F(n)}$, where $\epsilon$ represents the elasticity concerned). This optimal tax formula illustrates the fundamental trade-off between equity and efficiency. In particular, the tax rate rises if redistributional concerns become more pressing, as indicated by a larger distributional characteristic $\xi$. The denominator of (26) captures the distortionary costs of redistributive taxation in terms of the effective elasticity of the tax base. The first incomeweighted elasticity $\bar{\varepsilon}_{l t}$ is associated with the distortionary effect of taxes on labor supply. The second term in the denominator $(1-\alpha) \beta \bar{\varepsilon}_{y t}$ represents the human-capital distortion associated with a higher tax rate on account of the non-deductibility of education expenditures. The optimal marginal tax should be lower if larger compensated elasticities (in absolute value) indicate that redistributive taxes distort labor supply and human capital accumulation more substantially. These latter effects conform to standard Ramsey intuition.

We can substitute (10) and (16) to eliminate $\varepsilon_{l t}$ and $\varepsilon_{y t}$ in (26) to find

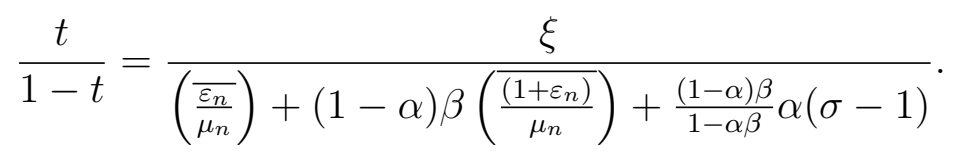

In the absence of a learning decision $(\beta=0)$, the effective elasticity of the tax base represented by the denominator at the right-hand side of (27) is simply the income-weighted compensated simple elasticity of labor supply $\bar{\varepsilon}_{n}$. Hence, our model nests the standard optimal linear income tax model (see Atkinson and Stiglitz (1980)). Even if all investments in human capital are tax deductible $(\alpha=1)$, the efficiency costs of taxation are higher than in the standard model without human capital accumulation $(\beta=0)$ because of the feedback effects of human capital accumulation on labor supply (i.e., $\left.\frac{\varepsilon_{n}}{\mu_{n}}=\frac{\varepsilon_{n}}{1-\beta\left(1+\varepsilon_{n}\right)}>\varepsilon_{n}\right)$; lower labor supply depresses learning, which harms the after-tax wage rate and thus further reduces labor supply. As a direct consequence, ceteris paribus the distributional characteristic $\xi$ and the simple compensated labor supply elasticities $\varepsilon_{n}$, endogenous learning reduces the optimal tax rate $t$. Non tax-deductibility of some human capital investments 
(i.e., $\alpha<1$ ) further decreases the optimal tax rate (at given $\xi$ and $\varepsilon_{n}$ ), especially if both the aggregate level and the composition of learning are sensitive to the tax rate (i.e., both $\beta$ and $\sigma$ are large).

\subsection{Optimal education policies}

This sub-section investigates optimal education policy if the government cannot simultaneously optimize its tax policy.

\subsubsection{Optimal education subsidies}

If the government can employ both $s_{x}$ and $s_{y}$ to optimize welfare, then the optimal linear education subsidies are found by manipulating the first-order conditions for maximizing the Lagrangian (21) with respect to $s_{x}$ and $s_{y}$. This yields the result that all inputs in learning should be equally taxed or subsidized (see appendix):

$$
\frac{-s_{x}}{1-s_{x}}=\frac{t-s_{y}}{1-s_{y}}
$$

so that the composition of human capital investment is not distorted.

The optimal levels of the education subsidies are given by (see appendix)

$$
\frac{-s_{x}}{\left(1-s_{x}\right)(1-t)}=\frac{t-s_{y}}{\left(1-s_{y}\right)(1-t)}=\frac{1}{(\overline{1 / \mu})}\left[\xi-\frac{t}{1-t}\left(\frac{\overline{\varepsilon_{n}}}{\mu_{n}}\right)\right],
$$

where $\overline{1 / \mu}$ represents the income-weighted elasticity $1 / \mu_{n}$, which captures the strength of the feedback effects between labor supply and human-capital formation (recall that $\mu_{n} \equiv 1-\beta\left(1+\varepsilon_{n}\right)$ ).

The term in square brackets at the far right-hand side of (29) measures the sub-optimality of the income tax (see expression (33) below). If this term is positive, income taxes are sub-optimally low and thus do not redistribute sufficient resources. Accordingly, the government employs also education taxes to redistribute from the rich, who learn more, to the poor. Education taxes are thus positive (i.e. $-s_{x}>0$ and $t-s_{y}>0$ ) if the government cannot tax labor income at all $(t=0)$. These education taxes are relatively large if the effective elasticity of the subsidy base is small; i.e., if the feedback effects between labor supply and learning are only weak and $\overline{1 / \mu}$ is small (ceteris paribus the distributional characteristic $\xi)$. 


\subsubsection{Optimal education subsidy on $x_{n}$ only}

If $y_{n}$ is not verifiable, the government cannot employ subsidies on $y_{n}$ so that $s_{y}=0$. In that case, the optimal linear education subsidy on $x_{n}$ is given by (see appendix)

$$
\frac{-s_{x}}{\left(1-s_{x}\right)(1-t)}=\frac{\left(\xi-\frac{t}{1-t}\left[\left(\frac{\overline{\varepsilon_{n}+1-\alpha}}{\mu_{n}}\right)-(1-\alpha) \sigma\right]\right)}{\alpha(\overline{1 / \mu})+(1-\alpha) \sigma},
$$

Without any instruments to tax income $(t=0)$, the government employs taxes on education $\left(s_{x}<0\right)$ to reduce inequality. With a Leontief production function for human capital $(\sigma=0)$, the government sets the same net tax on education as in the case in which the government has access to $s_{y}$ as well. To achieve this allocation, it raises the tax on $x_{n}$ above the corresponding $\operatorname{tax}-s_{x}$ with verifiable $y_{n}$ (compare (30) (and $\sigma=t=0$ ) with the optimal $s_{x}$ if both subsidy instruments are used (29)). With non-zero substitution between $x_{n}$ and $y_{n}(\sigma>0)$, a tax on the verifiable input in learning distorts the composition of human-capital investments. Hence, the government can no longer costlessly tax non-verifiable investments $y_{n}$ in an indirect way by levying a heavier tax on the verifiable component $x_{n}$. By doing so, the government imposes a smaller tax burden on education compared to the case in which both inputs into education are verifiable. Indeed, ceteris paribus the distributional characteristic $\xi$, more substitution between the two inputs into human capital accumulation reduces the optimal tax on learning, as such a tax distorts not only the aggregate level of human-capital accumulation (and thus labor supply) but also the composition of learning (see (30) with $t=0$ ).

With a Leontief production function of human capital, a positive income tax $t>0$, ceteris paribus reduces the optimal education tax. Intuitively, a positive income tax takes over the role of the education tax in redistributing income. With substantial substitution in human-capital accumulation (i.e., $\sigma$ is large), in contrast, the optimal education tax remains large in the presence of a positive income tax. The reason is that the education tax helps to offset the distortionary impact of income tax deductibility of $x_{n}$ on the composition of learning. Indeed, if the substitution elasticity $\sigma$ approaches infinity, the education tax is set so that it implies the same tax on $x_{n}$ as the income tax imposes on the non-tax deductible input $y_{n}$ (i.e., $\frac{-s_{x}}{\left(1-s_{x}\right)(1-t)}=\frac{t}{1-t}$, which corresponds to (28) with $s_{y}=0$ ). In this case, the government gives priority 
to offsetting the distortionary impact of the income tax on the composition rather than the aggregate level of learning.

\subsection{Optimal income taxation and education subsidies}

If the government can simultaneously employ all its policy instruments, the optimal subsidies on education are (see appendix)

$$
\begin{aligned}
& s_{x}=0, \\
& s_{y}=t .
\end{aligned}
$$

These expressions imply that the tax wedges on both inputs into human capital accumulation $\left(\Delta_{x}=-s_{x} p_{x}\right.$ and $\left.\Delta_{y}=\frac{\left(t-s_{y}\right) p_{y}}{1-t}\right)$ are zero. Optimal education policy thus eliminates learning distortions on account of redistributive taxation. The optimal subsidy $s_{y}$ ensures that non-deductible education expenses effectively become deductible against the labor income tax rate.

In the presence of this optimal education policy, the optimal linear tax rate is given by (see appendix)

$$
\frac{t}{1-t}=\frac{\xi}{\left(\frac{\overline{\varepsilon_{n}}}{\mu_{n}}\right)} .
$$

Comparing the optimal income tax with optimal education policy (33) to the optimal income tax without any education subsidies (27), we observe that the additional instrument of the education subsidy $s_{y}$ (ceteris paribus the distributional characteristic $\xi$ ) allows for a higher income tax. ${ }^{11}$ The reason is that the education subsidy eliminates the tax distortions on the aggregate level and composition of human capital accumulation. With a lower effective elasticity of the tax base implying smaller efficiency costs of redistributive income taxation, the government redistributes income more aggressively.

The deeper intuition for this result is as follows. The tax on labor income falls on income derived from human-capital formation, labor supply

\footnotetext{
${ }^{11}$ The optimal tax rate is still lower than without endogenous human capital accumulation $(\beta=0)$. The reason is that the positive feedback effects between labor supply and learning raise the effective labor-supply elasticity. This increases the deadweight loss associated with the labor-supply distortion, which (in contrast to the human capital distortion) is not affected by the education subsidy.
} 
and ability. With the optimal education subsidy (32) compensating individuals for the taxes imposed on the returns from learning, the labor income tax falls only on additional income from labor supply and the rents from ability. Hence, the education subsidy gives the government a more effective instrument to tax away the infra-marginal rents from ability without distorting the incentives to learn. Indeed, the optimal tax rate would approach $100 \%$ if labor supply was inelastic $\left(\varepsilon_{n}=0\right)$. The income tax cum education subsidy then effectively becomes Tinbergen's talent tax (i.e., a tax on rents from ability only).

Education subsidies increase if distributional concerns become more pressing, as indicated by a larger distributional characteristic $\xi$ (substitute (33) into (32) to eliminate $t$ ). This result may seem paradoxical because the more able individuals learn more, and thus benefit most from the education subsidies. However, this benefit for the most-skilled agents is more than offset by higher labor taxes imposing a heavier tax burden on the rents from ability. Clearly then, education subsidies and progressive taxation are Siamese twins. Indeed, both optimal education subsidies and marginal taxes are zero in the absence of redistributional considerations $(\xi=0)$.

\subsection{Optimal income taxation and imperfect education subsidies}

If the government cannot verify $y_{n}$, it must resort to subsidies on $x_{n}$ to offset the learning distortions imposed by the labor tax. The optimal linear taxes and education subsidies are obtained by manipulating the first-order conditions for maximizing the Lagrangian (21) with respect to $t$ and $s_{x}$. The optimal combination of subsidies and taxes satisfies (see appendix)

$$
\frac{s_{x}}{1-s_{x}}=\frac{(1-\sigma)(1-\alpha)}{1-(1-\alpha)(1-\sigma)} t
$$

An education subsidy $\left(s_{x}>0\right)$ alleviates the distortionary effect of the labor tax on aggregate learning. At the same time, however, it exacerbates the distortions of the tax system on the composition of learning. In particular, the tax system boosts the demand for $x_{n}$ at the expense of $y_{n}$ because only $x_{n}$ is tax deductible. By further reducing the effective cost of tax deductible inputs, an education subsidy causes even more substitution away from $y_{n}$ to the tax deductible inputs $x_{n}$. The sign of the optimal education subsidy 
depends on the relative strengths of these two effects. A large substitution elasticity $\sigma$ implies that tax distortions on the composition of learning dominate tax distortions on the aggregate level of learning. Hence, tax-deductible investments should be taxed so as to combat substitution between the two inputs. In contrast, if individuals cannot easily substitute $y_{n}$ for $x_{n}$ (i.e., $\sigma$ is small), $x_{n}$ is subsidized rather than taxed because subsidizing the observed input $x_{n}$ is a good substitute for subsidizing the non-observed input $y_{n}$, which the government would ideally like to subsidize (compare (32)).

The optimal linear income tax amounts to

$$
\frac{t}{1-t}=\frac{\xi}{\left(\overline{\frac{\varepsilon_{n}}{\mu_{n}}}\right)+\left(\frac{\overline{\beta\left(1+\varepsilon_{n}\right)}}{\mu_{n}}\right) \frac{\sigma(1-\alpha)}{\alpha+(1-\alpha) \sigma}} .
$$

With a Leontief production of human capital $(\sigma=0)$, the optimal income tax is the same as in the case in which all policy instruments are available (see (33)). Without substitution between $x_{n}$ and $y_{n}$, the government can costlessly subsidize non-verifiable inputs $y_{n}$ in an indirect way by subsidizing verifiable inputs $x_{n}$. With non-zero substitution between the two inputs $(\sigma>0)$, however, the government cannot costlessly mimic a subsidy on $y_{n}$ by subsidizing $x_{n}$, because subsidizing $x_{n}$ distorts the composition of human capital accumulation towards the excessive use of $x_{n}$. With an imperfect instrument to offset the distortionary impact of the tax system on $y_{n}$, the optimal linear income tax is lower compared to the optimal income tax with direct subsidies on $y_{n}$ (compare (35) and (33)).

With infinite substitution $(\sigma \rightarrow \infty)$, the optimal income tax with imperfect education subsidies equals the optimal income tax without any subsidies and tax deductible inputs (so that (35) coincides with (27) with $\alpha=0$ ). Indeed, in that case, the government finds it optimal to make $x_{n}$ effectively not tax deductible, so as ensure a level playing field with $y_{n}$. The Cobb Douglas case $(\sigma=1)$ is the only case in which the availability of $s_{x}$ does not raise the optimal tax rate (compare the optimal tax with $s_{x}(35)$ and the optimal tax at zero subsidies (27)). In that case, education subsidies cannot do anything to offset the distortions of the income tax on the composition and level of learning because the benefits of an educational subsidy in terms of more learning are exactly offset by the costs of such a subsidy in terms of a more distorted composition of learning (excessive use of $x_{n}$ ). Both with easy substitution $(\sigma>1)$ and with difficult substitution $(\sigma<1)$, the availability of $s_{x}$ allows the government to combat the human-capital distortions 
imposed by the labor income tax. With easy substitution, learning is taxed to alleviate the relatively large tax distortions on the composition of human capital. If substitution is difficult, in contrast, learning is subsidized, as the government gives priority to fighting tax distortions on the level rather than the composition of learning.

\section{Non-linear tax and education policies}

This section explores the robustness of our results by analyzing non-linear policy instruments. In particular, the government can levy a non-linear income tax $T\left(z_{n}-\left(p_{x} x_{n}-S_{x}\left(p_{x} x_{n}\right)\right)\right.$ on gross incomes $z_{n}$ minus net-ofsubsidy educational spending on $x_{n}$. The marginal income tax rate $T^{\prime} \equiv$ $d T\left(z_{n}-p_{x} x_{n}+S_{x}\left(p_{x} x_{n}\right)\right) / d\left(z_{n}-p_{x} x_{n}+S_{x}\left(p_{x} x_{n}\right)\right)$ can now differ across individuals with different incomes. Furthermore, the government may employ a non-linear subsidy on resources $x_{n}$ invested in education. The subsidy is denoted as $S_{x}\left(p_{x} x_{n}\right)$, where $S_{x}^{\prime} \equiv d S_{x}\left(p_{x} x_{n}\right) / d x_{n}$ represents the marginal subsidy rate on $x_{n}$. If non-deductible individual investments $p_{y} y_{n}$ are verifiable, the government can subsidize also $y_{n}$ through a non-linear subsidy $S_{y}\left(p_{y} y_{n}\right)$, with $S_{y}^{\prime} \equiv d S_{y}\left(p_{y} y_{n}\right) / d y_{n}$ denoting the marginal subsidy on $y_{n}$. The non-linear tax and educational subsidies imply stronger information requirements than the linear policy instruments explored in the previous section. In particular, the government must be able to verify gross incomes and inputs into learning of each individual rather than only the economy-wide aggregates.

\subsection{Individual optimization}

With these non-linear policy instruments, the individual's budget constraint reads as

$$
c_{n}=z_{n}-p_{x} x_{n}+S_{x}\left(p_{x} x_{n}\right)-T\left(z_{n}-p_{x} x_{n}+S_{x}\left(p_{x} x_{n}\right)\right)-p_{y} y_{n}+S_{y}\left(p_{y} y_{n}\right),
$$

where $z_{n} \equiv n \phi\left(x_{n}, y_{n}\right) l_{n}$.

Maximization of utility $u\left(c_{n}, l_{n}\right)$ subject to the household budget constraint yields

$$
\frac{-u_{l}}{u_{c}}=\left(1-T^{\prime}\right) n \phi\left(x_{n}, y_{n}\right),
$$


in addition to the first-order conditions for resources invested in education ${ }^{12}$

$$
\begin{gathered}
n l_{n} \phi_{x}=\left(1-S_{x}^{\prime}\right) p_{x} \\
\left(1-T^{\prime}\right) n l_{n} \phi_{y}=\left(1-S_{y}^{\prime}\right) p_{y} .
\end{gathered}
$$

\subsection{Government}

The government observes $z_{n}-p_{x} x_{n}+S_{x}\left(p_{x} x_{n}\right)$ (and $x_{n}$ and $y_{n}$ if it subsidizes education) and thereby controls $z_{n}-p_{n} x_{n}$ (and educational investments $x_{n}$ and $y_{n}$ if it subsidizes these investments) through the tax (and subsidy) schedule(s). In directly controlling the allocation, the government should respect the incentive-compatibility constraints, which require that each individual $n$ prefers the bundle $c_{n}, z_{n}, x_{n}, y_{n}$ intended for him over the bundles intended for others

$$
U\left(c_{n}, z_{n}, x_{n}, y_{n}, n\right) \geq U\left(c_{m}, z_{m}, x_{m}, y_{n}, n\right), \quad \forall m \in[\underline{n}, \bar{n}], \forall n \in[\underline{n}, \bar{n}]
$$

where $U\left(c_{n}, z_{n}, x_{n}, y_{n}, n\right) \equiv u\left(c_{n}, \frac{z_{n}}{n \phi\left(x_{n}, y_{n}\right)}\right)=u\left(c_{n}, l_{n}\right)$. These global incentivecompatibility constraints can be replaced by the (first-order) incentive-compatibility constraint using the Envelope Theorem (see, e.g., Mirrlees (1971)): ${ }^{13}$

$$
\frac{d u_{n}}{d n}=-u_{l}\left(c_{n}, l_{n}\right) \frac{l_{n}}{n}
$$

Utilizing Walras' law, we employ the economy's resource constraint ${ }^{14}$

$$
\int_{\underline{n}}^{\bar{n}}\left(n \phi\left(x_{n}, y_{n}\right) l_{n}-p_{x} x_{n}-p_{y} y_{n}-c_{n}-E\right) d F(n)=0
$$

rather than the government budget constraint.

\footnotetext{
${ }^{12}$ Second-order conditions for an interior solution are assumed to be satisfied. In particular, the restriction $\mu_{n} \equiv 1-\beta\left(1+\varepsilon_{n}\right)>0$ must hold.

${ }^{13}$ In adopting the first-order approach, we assume that the second-order conditions for the second-best allocation are met. This requires single crossing of the utility function with respect to all control variables in addition to all control variables being non-decreasing in ability at the optimum schedules. For an analysis of second-order conditions in optimal non-linear taxation problems, see Mirrlees (1986) and Ebert (1992).

${ }^{14}$ If the government implements an allocation that meets the individuals' budget constraints and the economy's resource constraint, the government budget constraint must be satisfied as well by Walras' law.
} 
We solve for the optimal allocation by applying the maximum principle and setting up a Hamiltonian $\mathcal{H}$, with $l_{n}$ (and, depending on the availability of non-linear education subsidies, $x_{n}$ and $y_{n}$ ) as control variable(s), $u_{n}$ as state variable, and a costate variable $\theta_{n}$ for the incentive-compatibility constraint (41):

$$
\begin{aligned}
\max _{\{l, x, y, u\}} \mathcal{H}= & \Psi\left(u_{n}\right) f(n)+\theta_{n} u_{l}\left(c_{n}, l_{n}\right) \frac{l_{n}}{n} \\
& +\lambda\left(n \phi\left(x_{n}, y_{n}\right) l_{n}-p_{x} x_{n}-p_{y} y_{n}-c_{n}\right) f(n),
\end{aligned}
$$

where $\lambda$ is the shadow value of the resource constraint. The transversality conditions are given by

$$
\lim _{n \rightarrow \bar{n}} \theta_{n}=0, \quad \lim _{n \rightarrow \underline{n}} \theta_{n}=0 .
$$

Having found the second-best allocation, we determine the optimal marginal taxes $T^{\prime}$ and subsidy rates $S_{x}^{\prime}$ and $S_{y}^{\prime}$ by employing the first-order condition(s) for individual optimization with respect to $l_{n}, x_{n}$, and $y_{n}$ (see (37), (38), and (39), respectively). Optimal consumption follows from the optimal levels of $l_{n}, y_{n}, x_{n}$, and the household budget constraint (36).

\subsection{Optimal income taxation}

In analogy of our discussion of linear policy instruments, we first explore the optimal income tax in the absence of education policy. By taking the first-order condition of the Hamiltonian (43) with respect to $l_{n}$, we derive the optimal marginal tax rates along the non-linear tax schedule (see appendix)

$$
\frac{T^{\prime}}{1-T^{\prime}}=\frac{u_{c} \theta_{n} / \lambda}{n f(n)}\left(1+\frac{1}{\varepsilon_{n}^{*}}\right)\left[\frac{\frac{\varepsilon_{n}}{\mu_{n}}}{\frac{\varepsilon_{n}}{\mu_{n}}+\frac{\beta\left(1+\varepsilon_{n}\right)\left(1-\alpha_{n}\right)}{\mu_{n}}+\frac{\left(1-\alpha_{n}\right) \beta}{\left(1-\alpha_{n} \beta\right)} \alpha_{n}\left(\sigma_{n}-1\right)}\right],
$$

where $\varepsilon_{n}^{*} \equiv\left(\frac{l u_{l l}}{u_{l}}-\frac{l u_{c l}}{u_{c}}\right)^{-1}$. With non-linear instruments both $\alpha_{n}$ and $\sigma_{n}$ are dependent on $n$, hence we use subscripts. The denominator in the term in square brackets in (45) equals the effective elasticity of the tax base in the corresponding expression of the linear income tax (27) (except that average elasticities feature in the expression of the optimal linear tax rate). The non-linear counterpart of $\xi$ is the term $u_{c} \theta_{n} / \lambda$, which measures the benefits of redistribution. In particular, $\theta_{n}$ denotes the welfare gain of redistributing 
income from individuals above ability $n$ to individuals below $n$, and depends both on the concavity of the social welfare function and the marginal utility of income. ${ }^{15}$ Furthermore, a larger number of individuals at ability $n$ (a larger density $f(n)$ ) and a higher ability level $n$ exacerbate the distortionary costs of high marginal rates at that ability level.

In the general case with partially deductible costs $\left(0 \leq \alpha_{n}<1\right.$ and $\beta>0)$ the optimal tax rates are reduced compared to the case with exogenous learning (ceteris paribus $\varepsilon_{n}^{*}, \varepsilon_{n}$, and $u_{c} \theta_{n} / \lambda$ ). The reason is that the tax system distorts not only labor supply, but also the level of learning because not all educational costs are deductible. The additional learning distortions yield lower optimal tax rates.

With substitution between $x_{n}$ and $y_{n}$ (if $\sigma_{n}>0$ ), the income tax distorts not only labor supply and the level of learning, but also the composition of learning by favoring deductible inputs $x_{n}$ over non tax-deductible inputs $y_{n}$. Hence, more substitution ceteris paribus depresses optimal tax rates. In fact, with easy substitution between deductible and non-deductible investments (i.e., $\sigma_{n}$ is large), the term in square brackets may be smaller compared to the case in which none of the costs of investment are deductible $\left(\alpha_{n}=0\right)$. Indeed, easy substitution implies that welfare losses due to a distorted composition of learning dominate those on account of a distorted level of learning. Hence, making some, but not all, investment costs deductible may harm welfare. With a Cobb Douglas learning technology $\left(\sigma_{n}=1\right)$, however, both effects cancel.

\subsection{Optimal education policies}

We now turn to the case in which the government has no access to the nonlinear income tax and can employ only education subsidies. By taking the first-order conditions of the Hamiltonian (43) with respect to $x_{n}$ and $y_{n}$, we derive the optimal marginal subsidy rates (see appendix)

$$
\frac{-S_{x}^{\prime}}{1-S_{x}^{\prime}}=\frac{-S_{y}^{\prime}}{1-S_{y}^{\prime}}=\frac{u_{c} \theta_{n} / \lambda}{n f(n)}\left(1+\frac{1}{\varepsilon_{n}^{*}}\right) \varepsilon_{n} .
$$

As in the linear case, the two education instruments are thus equal (compare (46) to the corresponding optimal linear education taxes (29) with $t=0$ ),

\footnotetext{
${ }^{15}$ From the transversality conditions follows that optimal marginal taxes are zero at the top and the bottom of the ability distribution, since $\theta_{\underline{n}}=\theta_{\bar{n}}=0$.
} 
which avoids distortions in the composition of human capital investments. Moreover, in the absence of the income tax, education is taxed in order to redistribute incomes away from the able agents who learn most.

\subsection{Optimal income taxation and education subsidies}

If the government simultaneously sets non-linear tax and education subsidy schedules, it determines the optimal allocation by using $x_{n}, y_{n}$, and $l_{n}$ as control variables. By manipulating the first-order condition of the Hamiltonian (43) with respect to these three controls, we derive optimal marginal tax rates and subsidy rates along the non-linear tax and subsidy schedules. From the first-order conditions for $x_{n}$ and $y_{n}$, we establish production efficiency in learning:

$$
\begin{aligned}
& n \phi_{x} l_{n}=p_{x}, \\
& n \phi_{y} l_{n}=p_{y} .
\end{aligned}
$$

Combining (47) with (38), and (48) with (39), we find

$$
\begin{gathered}
S_{x}^{\prime}\left(p_{x} x_{n}\right)=0 \\
S_{y}^{\prime}\left(p_{y} y_{n}\right)=T^{\prime}\left(z_{n}-p_{x} x_{n}+S\left(p_{x} x_{n}\right)\right) .
\end{gathered}
$$

Optimal education policy requires that all costs of education should effectively be tax deductible, just as in the linear case (compare (31) and (32)).

Optimal income tax rates along the non-linear tax schedule are (see appendix)

$$
\frac{T^{\prime}}{1-T^{\prime}}=\frac{u_{c} \theta_{n} / \lambda}{n f(n)}\left(1+\frac{1}{\varepsilon_{n}^{*}}\right) .
$$

We thus arrive at the same conclusion as with linear taxes: education subsidies allow for higher marginal tax rates by eliminating the distortionary impact of the labor income tax on the aggregate level and composition of human capital accumulation. In particular, comparing the optimal income tax rates with optimal education policy (51) to the optimal income tax without any education subsidies (45), we observe that the additional instrument of the education subsidy $s_{y}$ (ceteris paribus $\varepsilon_{n}^{*}, \varepsilon_{n}$, and $u_{c} \theta_{n} / \lambda$ ) allows for higher marginal taxes on labor income. Moreover, stronger redistributive motives, as reflected in higher values for $u_{c} \theta_{n} / \lambda$, result in higher education subsidies, even though the rich benefit more from education subsidies (substitute (51) into (50) to eliminate $T^{\prime}$ ). Indeed, whereas the tax system is targeted at 
redistribution, education subsidies offset the adverse impact of taxes on the incentives to accumulate human capital. Education subsidies and progressive taxation are therefore Siamese twins.

\subsection{Optimal income taxation and imperfect education subsidies}

If the government cannot verify $y_{n}$, it can employ only the non-linear tax system and subsidies on the deductible input $x_{n}$ to optimize social welfare. By taking the first-order condition of the Hamiltonian (43) with respect to $l_{n}$ and $x_{n}$ we derive the optimal marginal tax and subsidy rates. These instruments are related as follows (see appendix):

$$
\frac{S_{x}^{\prime}}{1-S_{x}^{\prime}}=\frac{\left(1-\alpha_{n}\right)\left(1-\sigma_{n}\right)}{1-\left(1-\alpha_{n}\right)\left(1-\sigma_{n}\right)} T^{\prime}
$$

which coincides with the corresponding expression for the linear income tax (see (34) and the explanation given there).

The optimal marginal income tax rates are given by

$$
\frac{T^{\prime}}{1-T^{\prime}}=\frac{u_{c} \theta_{n} / \lambda}{n f(n)}\left(1+\frac{1}{\varepsilon^{*}}\right)\left[\frac{\frac{\varepsilon_{n}}{\mu_{n}}}{\frac{\varepsilon_{n}}{\mu_{n}}+\frac{\beta\left(1+\varepsilon_{n}\right)}{\mu_{n}} \frac{\sigma_{n}\left(1-\alpha_{n}\right)}{\alpha_{n}+\left(1-\alpha_{n}\right) \sigma_{n}}}\right] .
$$

This formula again resembles the corresponding formula with linear policy instruments (35), with the denominator of the term in squared brackets coinciding with the effective elasticity of the tax base in (35) (except that average elasticities feature there). Optimal marginal tax rates with imperfect subsidies exceed the corresponding marginal tax rates without education subsidies (except if $\sigma_{n}=1$, see (45)), but are below the marginal tax rates if all three non-linear policy instruments are available (see (51)) (ceteris paribus $\varepsilon_{n}^{*}$, $\varepsilon_{n}$, and $\left.u_{c} \theta_{n} / \lambda\right)$. The substitution elasticity $\sigma_{n}$ between verifiable and nonverifiable inputs into human capital accumulation determines whether the optimal marginal tax rates are closer to the case with both or without any education subsidies. In particular, without much substitution, a subsidy on verifiable inputs mimics a subsidy on non-verifiable inputs. Therefore, tax distortions on human capital accumulation can be reduced without creating substantial distortions in the composition of human capital investments. Hence, the government can set relatively high tax rates. With easy substi-

tution, in contrast, the government should not use education subsidies to 
alleviate tax-induced learning distortions because these education subsidies substantially distort the composition of learning.

\section{$5 \quad$ Policy implications}

Our analysis has a number of important policy implications. In particular, if the government can observe educational inputs, it should optimally subsidize education to make all costs of education effectively tax deductible. As students typically do not earn high enough incomes to expense their educational costs from the income tax, governments should subsidize the costs of (higher) education at the marginal tax rate at which the marginal returns of that education are taxed.

To explore whether the current levels of education subsidies in several OECD countries are efficient, we calculate optimal education subsidies and compare them with actual subsidies. We focus on subsidies to higher education because compulsory schooling laws ensure that progressive taxes do not reduce participation in basic education. As a measure for $t$ ( or $T^{\prime}$ ), we employ marginal tax rates facing a worker earning $133 \%$ of the average production wage (see OECD (2002)). Public subsidy rates on the direct educational costs for tertiary education (see OECD 2003)) are used as a measure of $s$ (or $\left.S^{\prime}\right)$. All figures apply to 2000.

Table 1 contains the actual subsidies (as a percentage of direct costs of education) and marginal income taxes. Optimal education subsidies require that the costs of education be made effectively tax deductible from the income tax, so that the subsidy rate equals the marginal tax rate. Although actual subsidies are quite high, a substantial part of education subsidies can be justified by appealing to tax distortions on human capital formation. Indeed, one does not need to rely on capital market imperfections or externalities to argue in favor of substantial education subsidies.

Our analysis suggests also that education should be subsidized more heavily if countries feature more progressive tax systems. Figure 1 shows that this is indeed a stylized fact. As a corollary, countries reducing marginal taxes should cut education subsidies. As many countries have indeed cut marginal taxes in recent years, education subsidies can be reduced as well. Indeed, several countries have done exactly that.

The analysis sheds light on optimal education policies also if educational efforts cannot be adequately monitored. One interpretation of $x_{n}$ is time 
Table 1: Marginal tax rates and education subsidies (in \%)

\begin{tabular}{|c|c|c|}
\hline Country & Marginal tax rate & Marginal subsidy rate \\
\hline Korea & 27.0 & 23.3 \\
\hline United States & 46.6 & 33.9 \\
\hline Japan & 28.9 & 44.9 \\
\hline Australia & 43.5 & 51.0 \\
\hline Canada & 37.3 & 61.0 \\
\hline United Kingdom & 39.4 & 67.7 \\
\hline Spain & 48.6 & 74.4 \\
\hline Hungary & 63.6 & 76.7 \\
\hline Netherlands & 58.2 & 77.4 \\
\hline Italy & 55.6 & 77.5 \\
\hline Ireland & 55.8 & 79.2 \\
\hline Mexico & 26.7 & 79.4 \\
\hline Belgium & 70.7 & 85.2 \\
\hline Czech Republic & 48.1 & 85.5 \\
\hline France & 53.6 & 85.7 \\
\hline Sweden & 62.7 & 88.1 \\
\hline Slovakia & 49.4 & 91.2 \\
\hline Germany & 61.1 & 91.8 \\
\hline Portugal & 48.3 & 92.5 \\
\hline Iceland & 39.0 & 94.9 \\
\hline Turkey & 25.6 & 95.4 \\
\hline Norway & 55.1 & 96.2 \\
\hline Austria & 55.3 & 96.7 \\
\hline Finland & 63.2 & 97.2 \\
\hline Denmark & 63.3 & 97.6 \\
\hline Greece & 44.1 & 99.7 \\
\hline
\end{tabular}


invested in education, while $y_{n}$ can be interpreted as goods invested in education. Yet, the analysis allows for two alternative interpretations. First, $x_{n}$ and $y_{n}$ can be interpreted as basic and higher education, respectively. Since substitution between higher and basic education is very limited, the government may restore the correct incentives to accumulate human capital with substantial subsidies to basic education if it cannot verify students' efforts and resources invested in higher education. Indeed, this case corresponds closely to a Leontief production function of human capital.

As another alternative interpretation, $x_{n}$ and $y_{n}$ can be viewed as, respectively, formal and informal (parental) inputs into education. In this case formal, public inputs can be good substitutes for informal, private inputs, as argued by Becker and Tomes (1979). With parental inputs in human capital formation being very hard to observe, subsidizing formal inputs (schools, books, etc) may not be efficient because it merely crowds out informal parental efforts to educate their children.

\section{Conclusions}

This paper has studied the simultaneous setting of optimal redistributive income taxes and education subsidies. We showed that education subsidies

can be a powerful instrument to eliminate distortions in the accumulation of human capital caused by redistributive policies. Moreover, optimal marginal income tax rates can be higher if the government employs education subsidies to reduce the distortions associated with the redistribution of incomes. Education subsidies and redistribution of incomes are thus like Siamese twins - although the ones who benefit from the education subsidies also enjoy relatively high lifetime incomes. The more the government desires to help the poor, the more it should employ education subsidies to offset the learning distortions associated with redistribution. If not all educational efforts can be perfectly observed, however, the government cannot completely eliminate tax-distortions on human capital formation.

In future research, we intend to explore the consequences of non-pecuniary returns of education. If education is a consumption good and substantial returns on education are tacit, the tax wedge on learning is smaller because the returns escape the income tax. This weakens the case for education subsidies to correct for tax distortions (see also Alstadsaeter (2003)). We also would like to extend the current analysis to a more dynamic setting. In 
such a dynamic analysis, progressive tax schedules with rising marginal tax rates harm investment in human capital even if all costs of education are tax deductible. The reason is that the returns on learning are taxed at higher marginal rates than the marginal rates at which costs of learning (foregone earnings and direct costs) can be deducted.

\section{References}

Acemoglu, Daron J., and Joshua Angrist (2000), "How Large are the Social Returns to Education? Evidence from Compulsory Schooling Laws", NBER Macroeconomics Annual, 9-59.

Alstedsaeter, Annette (2003), "Does the Tax System Encourage too Much Education?", FinanzArchiv, 59, (1), 27-48.

Andersson, Fredrik, and Kai A. Konrad (2001), "Human Capital Investment and Globalization in Extortionary States", Journal of Public Economics, forthcoming.

Atkinson, Anthony B., and Joseph E. Stiglitz (1980), Lectures on Public Economics, New York: McGraw-Hill.

Becker, Gary S., and Nigel Tomes (1979), "Human Capital and the Rise and Fall of Families, Journal of Labor Economics, 4, (3), S1-S39.

Boadway, Robin, Nicolas Marceau, and Maurice Marchand (1996), "Investment in Education and the Time Inconsistency of Redistributive Tax Policy", Economica 63, 171-189.

Boskin, Michael (1975), "Notes on the Tax Treatment of Human Capital", NBER Working Paper 116.

Cameron, Stephen, and Christopher Taber (2000), "Borrowing Constraints and the Returns to Schooling", NBER Working Paper 7761.

Carneiro, Pedro, and James J. Heckman (2003). "Human Capital Policy", NBER Working Paper 9495.

Diamond, Peter A., and James A. Mirrlees (1971), "Optimal Taxation and Public Production I: Production Efficiency", American Economic Review $61,8-27$. 
Dur, Robert, and Coen N. Teulings (2001), "Education and Efficient Redistribution", Tinbergen Institute Discussion Paper 090/3.

Eaton, Jonathan, and Harvey S. Rosen (1980), "Taxation, Human Capital and Uncertainty", American Economic Review 70 (4), 705-715.

Ebert, Udo (1992), "A Reexamination of the Optimal Nonlinear Income Tax", Journal of Public Economics, 49, (1), 47-73.

Ewijk, Casper van, and Paul J.G. Tang (2000), "Efficient Progressive Taxes and Education Subsidies", CPB Research Memorandum 170, CPB Netherlands Bureau for Economic Policy Analysis.

Hare, Paul G., and David T. Ulph (1979), "On Education and Distribution", Journal of Political Economy, 87, S193-S212.

Heckman, James J., and Peter J. Klenow (1998), "Human Capital Policy", in: Boskin, Michael (ed.). Policies to Promote Human Capital Formation, Hoover Institution.

Jacobs, Bas and Sweder J. G. van Wijnbergen (2002), "Optimal Financing of Education with Capital and Insurance Markets Imperfections", mimeo: University of Amsterdam.

Judd, Kenneth L. (1999), "Optimal Taxation and Spending in General Competitive Growth Models", Journal of Public Economics, 71, 1-26.

Kotlikoff, Laurence J., and Lawrence H. Summers (1979), "Tax Incidence in a Life Cycle Model with Variable Labor Supply", Quarterly Journal of Economics, 93, 705-718.

Krueger, Alan B., and Mikael Lindahl (2002), "Education and Growth: Why and for Whom", Journal of Economic Literature, 39, (4), 11011136.

Lommerud, Kjell Erik (1989), "Educational Subsidies when Relative Income Matters", Oxford Economic Papers, 41, 640-652.

Milesi-Ferretti, Gian Maria, and Nouriel Roubini (1998), "On the Taxation of Human and Physical Capital in Models of Endogenous Growth", Journal of Public Economics, 70, 237-254. 
Mirrlees, James A. (1971), "An Exploration in the Theory of Optimum Income Taxation", Review of Economic Studies, 38, 175-208.

Nielsen, Søren B., and Peter B. Sørensen (1997), "On the Optimality of the Nordic System of Dual Income Taxation", Journal of Public Economics, 63, 311-329.

OECD (2002), Tax Data Base 2002, Paris: OECD.

OECD (2003), Education at a Glance 2003, Paris: OECD.

Shea, John (2000), "Does Parents' Money Matter?", Journal of Public Economics, $77,155-184$.

Trostel, Philip A. (1993), "The Effect of Taxation on Human Capital", Journal of Political Economy, 101, 327-350.

Ulph, David T. (1977). "On the Optimal Distribution of Income and Educational Expenditure", Journal of Public Economics, 8, 341-356.

\section{Appendix}

\section{Second-order conditions}

To derive the second-order conditions, we employ a two-step budgeting procedure. In the first stage, individuals select labor supply $l_{n}$ and aggregate investment in human capital $e_{n} \equiv \psi\left(x_{n}, y_{n}\right)$. Writing the household budget constraint as $c_{n}=(1-t) n \phi\left(e_{n}\right) l_{n}-p_{e} e_{n}+g$, where the price index of educational spending is $p_{e} \equiv\left((1-t)\left(1-s_{x}\right) p_{x} x_{n}+\left(1-s_{y}\right) p_{y} y_{n}\right) / e_{n}$, and substituting this budget constraint into the utility function $u\left(c_{n}, l_{n}\right)$ to eliminate $c_{n}$, we arrive at the following maximization problem

$$
\max _{\left\{l_{n}, e_{n}\right\}} U_{n}=u\left((1-t) n \phi(.) l_{n}-p_{e} e_{n}+g, l_{n}\right) .
$$

The first-order conditions are

$$
\begin{aligned}
& \frac{\partial U_{n}}{\partial l_{n}}=u_{c}(1-t) n \phi(.)+u_{l}=0 \\
& \frac{\partial U_{n}}{\partial e_{n}}=u_{c}\left[(1-t) n l_{n} \phi_{e}(.)-p_{e}\right]=0 .
\end{aligned}
$$


The second-order partial derivatives are ordered in the Hessian matrix $H$ :

$$
H \equiv\left[\begin{array}{cc}
u_{c l}(1-t) n \phi(.)+u_{l l} & u_{c}(1-t) n \phi_{e} \\
u_{c}(1-t) n \phi_{e} & u_{c}(1-t) n l_{n} \phi_{e e}
\end{array}\right]
$$

For utility to reach a maximum, the Hessian matrix should be negative definite. This is the case if the leading principal minors of $H$ switch sign. The first principal minor is $u_{l l}+u_{c l}(1-t) n \phi()=.u_{l l}-\frac{u_{c l} u_{l}}{u_{c}}<0$. Therefore, the second leading principal minor must be positive. Given the elasticities of the production function $\phi\left(e_{n}\right)=e_{n}^{\beta}$, this implies

$$
\beta\left(1+\varepsilon_{n}^{*}\right)<1
$$

where $\varepsilon_{n}^{*} \equiv\left(\frac{l u_{l l}}{u_{l}}-\frac{l u_{c l}}{u_{c}}\right)^{-1}$.

To relate this inequality to $\mu_{n} \equiv 1-\beta\left(1+\varepsilon_{n}\right)$, we link $\varepsilon_{n}^{*}$ to the compensated wage elasticity of labor supply $\varepsilon_{n}$. By totally differentiating the first-order condition $-u_{l} / u_{c}=w_{n}$ (where $w_{n}$ is the after-tax wage) and substituting the totally differentiated utility function (while holding utility constant, i.e., $\left.u_{c} d c_{n}+u_{l} d l_{n}=0\right)$ to eliminate $d c_{n}$, we can write the compensated wage elasticity of labor supply $\varepsilon_{n}$ as

$$
\varepsilon_{n} \equiv \frac{d l_{n}^{*}}{d w_{n}} \frac{w_{n}}{l_{n}^{*}}=\left(\left(\frac{l_{n} u_{l l}}{u_{l}}-\frac{l_{n} u_{c l}}{u_{c}}\right)-\left(\frac{-u_{l}}{u_{c}}\right)\left(\frac{l_{n} u_{c c}}{u_{c}}-\frac{l_{n} u_{c l}}{u_{l}}\right)\right)^{-1}
$$

so that $\varepsilon_{n}^{-1}=\left(\varepsilon_{n}^{*}\right)^{-1}+\rho$, where $\rho \equiv-\left(\frac{-u_{l}}{u_{c}}\right)\left(\frac{l_{n} u_{c c}}{u_{c}}-\frac{l_{n} u_{c l}}{u_{l}}\right) \geq 0$. So, we have $\varepsilon_{n} \leq \varepsilon_{n}^{*}$ and we find

$$
\mu_{n} \equiv 1-\beta\left(1+\varepsilon_{n}\right)>1-\beta\left(1+\varepsilon_{n}^{*}\right)>0
$$

Therefore, the second-order condition implies that $\mu_{n}>0$.

In the second stage of the budgeting procedure, individuals allocate their expenditures on education $e_{n}$ optimally over $x_{n}$ and $y_{n}$. Hence, they maximize $e_{n}=\psi\left(x_{n}, y_{n}\right)$ subject to the expenditure constraint: $p_{e} e_{n}=(1-t)(1-$ $\left.s_{x}\right) p_{x} x_{n}+\left(1-s_{y}\right) p_{y} y_{n}$. The resulting second-order condition $\psi_{x x} \psi_{y y}-\left(\psi_{x y}\right)^{2}>$ 0 is implied by concavity of the sub-production function for human capital $\psi\left(x_{n}, y_{n}\right)$. 


\section{Derivation of compensated elasticities}

We find the compensated behavioral elasticities with respect to policy variables by using (4) and (5). We multiply (4) by $(1-t) x_{n}$ and multiply (5) by $y_{n}$ and add the results. Using the property that $\psi\left(x_{n}, y_{n}\right)$ is homogeneous of degree one: $\psi_{x} x_{n}+\psi_{y} y_{n}=\psi\left(x_{n}, y_{n}\right)$, we then find

$$
\beta(1-t) n l_{n} \phi\left(e_{n}\right)=p_{e} e_{n},
$$

where $e_{n} \equiv \psi\left(x_{n}, y_{n}\right), p_{e} \equiv\left((1-t)\left(1-s_{x}\right) p_{x} x_{n}+\left(1-s_{y}\right) p_{y} y_{n}\right) / e_{n}$, and $\phi\left(e_{n}\right)=e_{n}^{\beta}$.

Log-linearizing (61) (using $\phi\left(e_{n}\right)=e_{n}^{\beta}$ ) and the definition of $p_{e}$ (using $e_{n} \equiv \psi\left(x_{n}, y_{n}\right)$ and $(4)$ and $\left.(5)\right)$, we arrive at

$$
\begin{gathered}
-\tilde{t}+\tilde{l}_{n}+\beta \tilde{e}_{n}=\tilde{p}_{e}+\tilde{e}_{n}, \\
\tilde{p}_{e}=-\alpha\left(\tilde{t}+\tilde{s}_{x}\right)-(1-\alpha) \tilde{s}_{y},
\end{gathered}
$$

where a tilde stands for a compensated relative change (i.e., $\tilde{l}_{n} \equiv d l_{n}^{*} / l_{n}^{*}$, $\tilde{x} \equiv d x_{n}^{*} / x_{n}^{*}$, et cetera), except for the tax rate and the subsidy rates where $\tilde{t} \equiv d t /(1-t)$ and $\tilde{s}_{i} \equiv d s_{i} /\left(1-s_{i}\right), i=x, y$.

$\alpha \equiv \frac{x_{n} \psi_{x}}{\psi}=\frac{(1-t)\left(1-s_{x}\right) p_{x} x_{n}}{p_{e} e_{n}}$ does not depend on ability with linear taxes and subsidies. The reason is that (4) and (5) imply that the marginal rate of transformation does not depend on $n$ :

$$
\frac{\psi_{x}}{\psi_{y}}=\frac{(1-t)\left(1-s_{x}\right) p_{x}}{\left(1-s_{y}\right) p_{y}} .
$$

$\psi_{x}$ and $\psi_{y}$ are functions of $x_{n} / y_{n}$ only (since $\psi($.$) is homogeneous of the$ first degree). Hence, (64) determines the ratio of the two inputs $x_{n} / y_{n}$ as a function of $\frac{(1-t)\left(1-s_{x}\right) p_{x}}{\left(1-s_{y}\right) p_{y}}$ only. Hence, if policy instruments are linear, $\alpha=$ $\frac{(1-t)\left(1-s_{x}\right) p_{x} x_{n}}{(1-t)\left(1-s_{x}\right) p_{x} x_{n}+\left(1-s_{y}\right) p_{y} y_{n}}=\frac{(1-t)\left(1-s_{x}\right) p_{x}\left(x_{n} / y_{n}\right)}{(1-t)\left(1-s_{x}\right) p_{x}\left(x_{n} / y_{n}\right)+\left(1-s_{y}\right) p_{y}}$ depends only on $(1-$ $t)\left(1-s_{x}\right) p_{x}$ and $\left(1-s_{y}\right) p_{y}$, which do not depend on ability. However, if policy instruments are non-linear (and we replace $s_{x}$ by $S_{x}^{\prime}\left(p_{x} x_{n}\right), s_{x}$ by $S_{x}^{\prime}\left(p_{x} x_{n}\right)$ and $t$ by $T^{\prime}\left(z_{n}-p_{x} x_{n}+S_{x}\left(p_{x} x_{n}\right)\right)$ this is no longer true. Therefore, with the non-linear policy instruments, we will use a subscript $n$ for both $\alpha$ and $\sigma$.

Expression (8) implies that compensated labor supply depends only on the after-tax wage rate $w \equiv(1-t) n \phi\left(x_{n}, y_{n}\right)=(1-t) n e_{n}^{\beta}$. We can write

$$
\tilde{l}_{n}=\varepsilon_{n}\left(-\tilde{t}+\beta \tilde{e}_{n}\right)
$$


where $\varepsilon_{n}$ is the compensated wage elasticity of labor supply, i.e., $\varepsilon_{n}=\frac{\partial l_{n}^{*}}{\partial w_{n}} \frac{w_{n}}{l_{n}^{*}}$.

Substituting (65) and (63) into (62) to eliminate, respectively, $\tilde{l}_{n}$ and $\tilde{p}_{e}$, we can solve for $\tilde{\phi}_{n}=\beta \tilde{e}_{n}$ :

$$
\tilde{\phi}_{n}=\beta \tilde{e}_{n}=\frac{\beta}{\mu_{n}}\left(\left(\alpha-\left(1+\varepsilon_{n}\right)\right) \tilde{t}+\alpha \tilde{s}_{x}+(1-\alpha) \tilde{s}_{y}\right)
$$

where $\mu_{n} \equiv 1-\left(1+\varepsilon_{n}\right) \beta>0$. Substituting (66) into (65), we solve for $\tilde{l}_{n}$ :

$$
\tilde{l}_{n}=\frac{\beta \varepsilon_{n}}{\mu_{n}}\left(\alpha \tilde{s}_{x}+(1-\alpha) \tilde{s}_{y}\right)-\frac{\varepsilon_{n}(1-\alpha \beta)}{\mu_{n}} \tilde{t} .
$$

We find $x_{n}$ and $y_{n}$ by differentiating $e_{n} \equiv \psi\left(x_{n}, y_{n}\right)$ and using (4) and (5) to eliminate $\psi_{x}$ and $\psi_{y}$ to arrive at

$$
\tilde{e}=\alpha \tilde{x}+(1-\alpha) \tilde{y}
$$

Differentiation of (64) yields

$$
\tilde{x}-\tilde{y}=\sigma\left(\tilde{t}+\tilde{s}_{x}-\tilde{s}_{y}\right)
$$

where $\sigma \equiv-d\left(\frac{x_{n}}{y_{n}}\right) / d\left(\frac{\psi_{x}}{\psi_{y}}\right)$ is the elasticity of substitution between the two inputs in the production of human capital. This substitution elasticity depends only on $\frac{x_{n}}{y_{n}}$ and is thus independent of ability (just like $\alpha$ ). From (68) and (69), we can express $\tilde{x}$ and $\tilde{y}$ in terms of $\tilde{e}$ and substituting (66) to eliminate $\tilde{e}$, we find:

$$
\begin{gathered}
\tilde{x}=\frac{\left(\alpha-\left(1+\varepsilon_{n}\right)\right) \tilde{t}+\alpha \tilde{s}_{x}+(1-\alpha) \tilde{s}_{y}}{\mu_{n}}+(1-\alpha) \sigma\left(\tilde{t}+\tilde{s}_{x}-\tilde{s}_{y}\right), \\
\tilde{y}=\frac{\left(\alpha-\left(1+\varepsilon_{n}\right)\right) \tilde{t}+\alpha \tilde{s}_{x}+(1-\alpha) \tilde{s}_{y}}{\mu_{n}}-\alpha \sigma\left(\tilde{t}+\tilde{s}_{x}-\tilde{s}_{y}\right) .
\end{gathered}
$$

(67), (70) and (71) yield the elasticities in the main text.

\section{First-order conditions linear tax and education policies}

We apply Roy's lemma to derive the following properties:

$$
\frac{\partial v\left(g, t, s_{x}, s_{y}, n\right)}{\partial g}=\eta_{n}
$$




$$
\begin{gathered}
\frac{\partial v\left(g, t, s_{x}, s_{y}, n\right)}{\partial t}=-\eta_{n}\left(n \phi\left(x_{n}, y_{n}\right) l_{n}-\left(1-s_{x}\right) p_{x} x_{n}\right) \\
\frac{\partial v\left(g, t, s_{x}, s_{y}, n\right)}{\partial s_{x}}=\eta_{n}(1-t) p_{x} x_{n} \\
\frac{\partial v\left(g, t, s_{x}, s_{y}, n\right)}{\partial s_{y}}=\eta_{n} p_{y} y_{n}
\end{gathered}
$$

where $\eta_{n}$ denotes private marginal utility of income for individual with ability $n$.

The first-order conditions for maximization of social welfare (21) with respect to $t, s_{x}$, and $s_{y}$ are given by

$$
\begin{aligned}
\frac{\partial \mathcal{L}}{\partial t}= & \int_{\underline{n}}^{\bar{n}}\left(-\Psi^{\prime} \eta_{n}+\lambda\right)\left(n l_{n} \phi\left(x_{n}, y_{n}\right)-\left(1-s_{x}\right) p_{x} x_{n}\right) d F(n)+ \\
& \int_{\underline{n}}^{\bar{n}} \lambda\left(\operatorname{tn} \phi\left(x_{n}, y_{n}\right) \frac{\partial l_{n}}{\partial t}+\Delta_{x} \frac{\partial x_{n}}{\partial t}+\Delta_{y} \frac{\partial y_{n}}{\partial t}\right) d F(n)=0, \\
\frac{\partial \mathcal{L}}{\partial s_{x}}= & \int_{\underline{n}}^{\bar{n}}\left(\Psi^{\prime} \eta_{n}-\lambda\right)(1-t) p_{x} x_{n} d F(n)+ \\
& \int_{\underline{n}}^{\bar{n}} \lambda\left(\operatorname{tn} \phi\left(x_{n}, y_{n}\right) \frac{\partial l_{n}}{\partial s_{x}}+\Delta_{x} \frac{\partial x_{n}}{\partial s_{x}}+\Delta_{y} \frac{\partial y_{n}}{\partial s_{x}}\right) d F(n)=0, \\
\frac{\partial \mathcal{L}}{\partial s_{y}}= & \int_{\underline{n}}^{\bar{n}}\left(\Psi^{\prime} \eta_{n}-\lambda\right) p_{y} y_{n} d F(n)+ \\
& \int_{\underline{n}}^{\bar{n}} \lambda\left(\operatorname{tn} \phi\left(x_{n}, y_{n}\right) \frac{\partial l_{n}}{\partial s_{y}}+\Delta_{x} \frac{\partial x_{n}}{\partial s_{y}}+\Delta_{y} \frac{\partial y_{n}}{\partial s_{y}}\right) d F(n)=0,
\end{aligned}
$$

where we used (73), (74), and (75). These equations can be simplified using the Slutsky equations for labor supply and investment in human capital (a derivative with an asterisk denotes a compensated change): $\frac{\partial l_{n}}{\partial t} \equiv \frac{\partial l_{n}^{*}}{\partial t}-$ $\left(n \phi\left(x_{n}, y_{n}\right) l_{n}-\left(1-s_{x}\right) p_{x} x_{n}\right) \frac{\partial l_{n}}{\partial g}, \frac{\partial x_{n}}{\partial t} \equiv \frac{\partial x_{n}^{*}}{\partial t}-\left(n \phi\left(x_{n}, y_{n}\right) l_{n}-\left(1-s_{x}\right) p_{x} x_{n}\right) \frac{\partial x_{n}}{\partial g}$, $\frac{\partial y_{n}}{\partial t} \equiv \frac{\partial y_{n}^{*}}{\partial t}-\left(n \phi\left(x_{n}, y_{n}\right) l_{n}-\left(1-s_{x}\right) p_{x} x_{n}\right) \frac{\partial y_{n}}{\partial g}, \frac{\partial l_{n}}{\partial s_{x}} \equiv \frac{\partial l_{n}^{*}}{\partial s_{x}}+(1-t) p_{x} x_{n} \frac{\partial l_{n}}{\partial g}$, $\frac{\partial x_{n}}{\partial s_{x}} \equiv \frac{\partial x_{n}^{*}}{\partial s_{x}}+(1-t) p_{x} x_{n} \frac{\partial x_{n}}{\partial g}, \frac{\partial y_{n}}{\partial s_{x}} \equiv \frac{\partial y_{n}^{*}}{\partial s_{x}}+(1-t) p_{x} x_{n} \frac{\partial y_{n}}{\partial g}, \frac{\partial l_{n}}{\partial s_{y}} \equiv \frac{\partial l_{n}^{*}}{\partial s_{y}}+p_{y} y_{n} \frac{\partial l_{n}}{\partial g}$, $\frac{\partial x_{n}}{\partial s_{y}} \equiv \frac{\partial x_{n}^{*}}{\partial s_{y}}+p_{y} y_{n} \frac{\partial x_{n}}{\partial g}$, and $\frac{\partial y_{n}}{\partial s_{y}} \equiv \frac{\partial y_{n}^{*}}{\partial s_{y}}+p_{y} y_{n} \frac{\partial y_{n}}{\partial g}$. Substitution of the last 
nine equations, together with the definition of $b_{n}$ from (23) in the first-order conditions for $t, s_{x}$ and $s_{y}$, yields

$$
\begin{gathered}
\int_{\underline{n}}^{\bar{n}}\left(\left(1-b_{n}\right)\left(n l_{n} \phi(.)-\left(1-s_{x}\right) p_{x} x_{n}\right)+\operatorname{tn} \phi(.) \frac{\partial l_{n}^{*}}{\partial t}+\Delta_{x} \frac{\partial x_{n}^{*}}{\partial t}+\Delta_{y} \frac{\partial y_{n}^{*}}{\partial t}\right) d F(n)=0 \\
\int_{\underline{n}}^{\bar{n}}\left(\left(b_{n}-1\right)(1-t) p_{x} x_{n}+\operatorname{tn} \phi(.) \frac{\partial l_{n}^{*}}{\partial s_{x}}+\Delta_{x} \frac{\partial x_{n}^{*}}{\partial s_{x}}+\Delta_{y} \frac{\partial y_{n}^{*}}{\partial s_{x}}\right) d F(n)=0 \\
\int_{\underline{n}}^{\bar{n}}\left(\left(b_{n}-1\right) p_{y} y_{n}+\operatorname{tn} \phi(.) \frac{\partial l_{n}^{*}}{\partial s_{y}}+\Delta_{x} \frac{\partial x_{n}^{*}}{\partial s_{y}}+\Delta_{y} \frac{\partial y_{n}^{*}}{\partial s_{y}}\right) d F(n)=0
\end{gathered}
$$

The first-order condition for the tax rate (79) can be rewritten using the tax elasticities $\left(\varepsilon_{j t} \equiv \frac{\partial j_{n}}{\partial t} \frac{(1-t)}{j_{n}} ; j=l^{*}, x^{*}, y^{*}\right), \Delta_{x}$, and $\Delta_{y}$ :

$$
\begin{aligned}
& \int_{\underline{n}}^{\bar{n}}\left(b_{n}-1\right)\left(n l_{n} \phi(.)-\left(1-s_{x}\right) p_{x} x_{n}\right) d F(n) \\
= & \int_{\underline{n}}^{\bar{n}}\left(\frac{t}{1-t} n \phi(.) l_{n} \varepsilon_{l t}-\frac{s_{x} p_{x} x_{n}}{1-t} \varepsilon_{x t}+\frac{\left(t-s_{y}\right)}{(1-t)} \frac{p_{y} y_{n}}{(1-t)} \varepsilon_{y t}\right) d F(n) .
\end{aligned}
$$

We use now (6) and (7) to write $p_{x} x_{n}$ and $p_{y} y_{n}$ in terms of $n l_{n} \phi($.$) to$ yield (after dividing by $(1-\alpha \beta)$ ):

$$
\begin{aligned}
& \int_{\underline{n}}^{\bar{n}}\left(b_{n}-1\right) n l_{n} \phi(.) d F(n)=\frac{t}{1-t} \int_{\underline{n}}^{\bar{n}} \frac{\varepsilon_{l t}}{(1-\alpha \beta)} n l_{n} \phi(.) d F(n) \\
& -\frac{s_{x}}{\left(1-s_{x}\right)(1-t)} \int_{\underline{n}}^{\bar{n}} \frac{\alpha \beta \varepsilon_{x t}}{(1-\alpha \beta)} n l_{n} \phi(.) d F(n) \\
& +\frac{t-s_{y}}{\left(1-s_{y}\right)(1-t)} \int_{\underline{n}}^{\bar{n}} \frac{(1-\alpha) \beta \varepsilon_{y t}}{(1-\alpha \beta)} n l_{n} \phi(.) d F(n) .
\end{aligned}
$$

Similarly, we can rewrite the first-order condition for the subsidy $s_{x}(80)$ by using the subsidy elasticities $\left(\varepsilon_{j s_{x}} \equiv \frac{\partial j_{n}}{\partial s_{x}} \frac{\left(1-s_{x}\right)}{j_{n}} ; j=l^{*}, x^{*}, y^{*}\right), \Delta_{x}$, and $\Delta_{y}$ :

$$
\begin{aligned}
& \int_{\underline{n}}^{\bar{n}}\left(1-b_{n}\right)(1-t) p_{x} x_{n} d F(n) \\
= & \int_{\underline{n}}^{\bar{n}}\left(\frac{t}{1-s_{x}} n l_{n} \phi(.) \varepsilon_{l s_{x}}-\frac{s_{x} p_{x} x_{n}}{1-s_{x}} \varepsilon_{x s_{x}}+\frac{\left(t-s_{y}\right) p_{y} y_{n}}{(1-t)\left(1-s_{x}\right)} \varepsilon_{y s_{x}}\right) d F(n) .
\end{aligned}
$$


We use now (6) and (7) to write $p_{x} x_{n}$ and $p_{y} y_{n}$ in terms of $n l_{n} \phi($.$) to$ obtain (after dividing through by $\frac{(1-t) \alpha \beta}{\left(1-s_{x}\right)}$ )

$$
\begin{aligned}
& \int_{\underline{n}}^{\bar{n}}\left(1-b_{n}\right) n l_{n} \phi(.) d F(n)=\frac{t}{1-t} \int_{\underline{n}}^{\bar{n}} \frac{\varepsilon_{l s_{x}}}{\alpha \beta} n l_{n} \phi(.) d F(n) \\
& -\frac{s_{x}}{\left(1-s_{x}\right)(1-t)} \int_{\underline{n}}^{\bar{n}} \varepsilon_{x s_{x}} n l_{n} \phi(.) d F(n) \\
& +\frac{\left(t-s_{y}\right)}{\left(1-s_{y}\right)(1-t)} \int_{\underline{n}}^{\bar{n}} \frac{(1-\alpha) \varepsilon_{y s_{x}}}{\alpha} n l_{n} \phi(.) d F(n) .
\end{aligned}
$$

Finally, we rewrite the first-order condition for $s_{y}$ (81) using the subsidy elasticities $\left(\varepsilon_{j s_{y}} \equiv \frac{\partial j_{n}}{\partial s_{y}} \frac{\left(1-s_{y}\right)}{j_{n}} ; j=l^{*}, x^{*}, y^{*}\right), \Delta_{x}$, and $\Delta_{y}$ :

$$
\begin{aligned}
& \int_{\underline{n}}^{\bar{n}}\left(1-b_{n}\right) p_{y} y_{n} d F(n) \\
= & \int_{\underline{n}}^{\bar{n}}\left(\frac{t}{1-s_{y}} n \phi(.) l_{n} \varepsilon_{l s_{y}}-\frac{s_{x} p_{x} x_{n}}{1-s_{y}} \varepsilon_{x s_{y}}+\frac{t-s_{y} p_{y} y_{n}}{(1-t)\left(1-s_{y}\right)} \varepsilon_{y s_{y}}\right) d F(n) .
\end{aligned}
$$

We use now (6) and (7) to write $p_{x} x_{n}$ and $p_{y} y_{n}$ in terms of $n l_{n} \phi($.$) to obtain$ (after dividing through by $\frac{(1-t) v}{\left(1-s_{y}\right)}$ )

$$
\begin{aligned}
& \int_{\underline{n}}^{\bar{n}}\left(1-b_{n}\right) n l_{n} \phi(.) d F(n)=\frac{t}{1-t} \int_{\underline{n}}^{\bar{n}} \frac{\varepsilon_{l s_{y}}}{(1-\alpha) \beta} n l_{n} \phi(.) d F(n) \\
& -\frac{s_{x}}{\left(1-s_{x}\right)(1-t)} \int_{\underline{n}}^{\bar{n}} \frac{\alpha \varepsilon_{x s_{y}}}{(1-\alpha)} n l_{n} \phi(.) d F(n) \\
& +\frac{t-s_{y}}{\left(1-s_{y}\right)(1-t)} \int_{\underline{n}}^{\bar{n}} \varepsilon_{y s_{y}} n l_{n} \phi(.) d F(n) .
\end{aligned}
$$

\section{Optimal linear income taxation}

Together with the definition of the distributional characteristic (25), the firstorder condition for $t$ (83) yields the optimal linear income tax (26) (with $\left.s_{x}=s_{y}=0\right)$. 


\section{Optimal linear education subsidies}

If we subtract (87) from (85), we find

$$
\begin{aligned}
& \frac{t}{1-t} \int_{\underline{n}}^{\bar{n}}\left(\frac{\varepsilon_{l s_{x}}}{\alpha \beta}-\frac{\varepsilon_{l s_{y}}}{(1-\alpha) \beta}\right) n l_{n} \phi(.) d F(n) \\
= & \frac{s_{x}}{\left(1-s_{x}\right)(1-t)} \int_{\underline{n}}^{\bar{n}}\left(\varepsilon_{x s_{x}}-\frac{\alpha \varepsilon_{x s_{y}}}{(1-\alpha)}\right) n l_{n} \phi(.) d F(n) \\
& -\frac{t-s_{y}}{\left(1-s_{y}\right)(1-t)} \int_{\underline{n}}^{\bar{n}}\left(\frac{(1-\alpha) \varepsilon_{y s_{x}}}{\alpha}-\varepsilon_{y s_{y}}\right) n l_{n} \phi(.) d F(n) .
\end{aligned}
$$

Expressing these elasticities in terms of the compensated labor supply elasticity $\varepsilon_{n}$ and the parameters of the production function of human capital (see the expressions at the end of sub-section 3.1), we find that $\frac{\varepsilon_{l_{x x}}}{\alpha \beta}-\frac{\varepsilon_{l s_{y}}}{(1-\alpha) \beta}=0$, $\varepsilon_{x s_{x}}-\frac{\alpha \varepsilon_{x s_{y}}}{(1-\alpha)}=\sigma$ and $\frac{(1-\alpha) \varepsilon_{y s_{x}}}{\alpha}-\varepsilon_{y s_{y}}=-\sigma$ so that

$$
\frac{-s_{x}}{\left(1-s_{x}\right)(1-t)}=\frac{t-s_{y}}{\left(1-s_{y}\right)(1-t)}
$$

if $\sigma>0$. Substituting (89) back into (85) to eliminate $\frac{t-s_{y}}{\left(1-s_{y}\right)(1-t)}$ and using expressions at the end of sub-section 3.1 to eliminate the elasticities, we arrive at (29). Employing the same expressions to rewrite (85), we establish (30).

\section{Optimal linear income taxation and linear education subsidies}

Adding (87) to (83) and using (89) to eliminate $\frac{-s_{x}}{\left(1-s_{x}\right)(1-t)}$, we find

$$
\begin{aligned}
& \frac{t}{1-t} \int_{\underline{n}}^{\bar{n}}\left(\frac{\varepsilon_{l t}}{(1-\alpha \beta)}+\frac{\varepsilon_{l s_{y}}}{(1-\alpha) \beta}\right) n l_{n} \phi(.) d F(n)= \\
& -\frac{t-s_{y}}{\left(1-s_{y}\right)(1-t)} \int_{\underline{n}}^{\bar{n}}\left(\frac{\alpha \beta \varepsilon_{x t}}{(1-\alpha \beta)}+\frac{(1-\alpha) \beta \varepsilon_{y t}}{(1-\alpha \beta)}+\frac{\alpha \varepsilon_{x s_{y}}}{(1-\alpha)}+\varepsilon_{y s_{y}}\right) n l_{n} \phi(.) d F(n)
\end{aligned}
$$

Using the expressions for the elasticities, we derive that $\frac{\varepsilon_{l t}}{(1-\alpha \beta)}+\frac{\varepsilon_{l_{y}}}{(1-\alpha) \beta}=0$ and $\frac{\alpha \beta \varepsilon_{x t}}{(1-\alpha \beta)}+\frac{(1-\alpha) \beta \varepsilon_{y t}}{(1-\alpha \beta)}+\frac{\alpha \varepsilon_{x s_{y}}}{(1-\alpha)}+\varepsilon_{y s_{y}}=\frac{-1}{1-\alpha \beta}$, so that

$$
\frac{s_{y}-t}{\left(1-s_{y}\right)(1-t)}\left(\int_{\underline{n}}^{\bar{n}} \frac{1}{1-\alpha \beta} n \phi\left(x_{n}, y_{n}\right) l_{n} d F(n)\right)=0 .
$$


Since the term between parentheses is non zero, we must have $s_{y}=t$. (89) then yields $s_{x}=0$. Substituting these results in (83) and employing the expressions at the end of sub-section 3.1 to write the elasticities in terms of $\varepsilon_{n}$ and the parameters of the production function for human capital, we obtain (33).

\section{Optimal linear income taxation and imperfect linear ed- ucation subsidies}

Adding (83) and (85), we establish

$$
\begin{aligned}
& \frac{t}{1-t} \int_{\underline{n}}^{\bar{n}}\left(\frac{\varepsilon_{l t}}{(1-\alpha \beta)}+\frac{\varepsilon_{l s_{x}}}{\alpha \beta}\right) n l_{n} \phi(.) d F(n) \\
= & \frac{s_{x}}{\left(1-s_{x}\right)(1-t)} \int_{\underline{n}}^{\bar{n}}\left(\frac{\alpha \beta \varepsilon_{x t}}{1-\alpha \beta}+\varepsilon_{x s_{x}}\right) n l_{n} \phi(.) d F(n) \\
& -\frac{\left(t-s_{y}\right)}{\left(1-s_{y}\right)(1-t)} \int_{\underline{n}}^{\bar{n}}\left(\frac{(1-\alpha) \beta \varepsilon_{y t}}{(1-\alpha \beta)}+\frac{(1-\alpha) \varepsilon_{y s_{x}}}{\alpha}\right) n l_{n} \phi(.) d F(n) .
\end{aligned}
$$

Expressing the elasticities in terms of the parameters of the production function of human capital and the compensated wage elasticity of labor supply $\varepsilon_{n}$, we find for the terms in parentheses: $\frac{\varepsilon_{l t}}{(1-\alpha \beta)}+\frac{\varepsilon_{l s_{x}}}{\alpha \beta}=0, \frac{\alpha \beta \varepsilon_{x t}}{1-\alpha \beta}+\varepsilon_{x s_{x}}=\frac{\alpha+(1-\alpha) \sigma}{1-\alpha \beta}$ and $\frac{(1-\alpha) \beta \varepsilon_{y t}}{(1-\alpha \beta)}+\frac{(1-\alpha) \varepsilon_{y s_{x}}}{\alpha}=\frac{(1-\alpha)(1-\sigma)}{1-\alpha \beta}$. Substituting these expressions, which are independent of ability $n$, into (92), we find

$$
\frac{s_{x}}{1-s_{x}}=\frac{(1-\alpha)(1-\sigma)}{1-(1-\alpha)(1-\sigma)} t
$$

Substitution of (93) into (85) and using the definitions for the elasticities, we arrive at (35).

\section{Optimal non-linear income taxation}

If the government has the non-linear income tax as its only policy instrument, it employs only $l_{n}$ as a control variable, taking into account the indirect effects of changing that control variable $l_{n}$ and the state variable $u_{n}$ on $x_{n}, y_{n}$ and $c_{n}$. The first-order condition for optimizing the Hamiltonian with respect to 
$l_{n}$ amounts to

$$
\begin{aligned}
\frac{\partial \mathcal{H}}{\partial l_{n}}= & \lambda\left(n \phi\left(x_{n}, y_{n}\right)-\left.\frac{d c_{n}}{d l_{n}}\right|_{\bar{u}}\right) f(n)+ \\
& \lambda\left(\left.\left(n \phi_{x} l_{n}-p_{x}\right) \frac{d x_{n}}{d l_{n}}\right|_{\bar{u}}+\left.\left(n \phi_{y} l_{n}-p_{y}\right) \frac{d y_{n}}{d l_{n}}\right|_{\bar{u}}\right) f(n)+ \\
& \frac{\theta_{n}}{n}\left(u_{l}+l_{n} u_{l l}+\left.l_{n} u_{l c} \frac{d c_{n}}{d l_{n}}\right|_{\bar{u}}\right)=0 .
\end{aligned}
$$

Substituting $\left.\frac{d c_{n}}{d l_{n}}\right|_{\bar{u}}=-\frac{u_{l}}{u_{c}}=\left(1-T^{\prime}\right) n \phi($.$) (derived by differentiating$ utility $u\left(c_{n}, l_{n}\right)$ and substituting the marginal rate of substitution between work and consumption (37)), the private first-order condition for $x_{n}$ (38) $\left(n \phi_{x} l_{n}-p_{x}=0\right.$ with $\left.S_{x}=0\right)$, the private first-order condition for $y_{n}$ (39) $\left(n \phi_{y} l_{n}-p_{y}=\frac{T^{\prime} p_{y}}{1-T^{\prime}}\right.$ and $\left.S_{y}=0\right)$, and $u_{l}=-u_{c}\left(1-T^{\prime}\right) n \phi($.$) (derived from$ (37)), yields the optimal marginal income tax rates:

$$
\frac{T^{\prime}}{1-T^{\prime}}=\frac{u_{c} \theta_{n} / \lambda}{n f(n)}\left(1+\frac{1}{\varepsilon_{n}^{*}}\right)\left(\frac{1}{1+v_{n} \varepsilon_{y l}}\right),
$$

where $\varepsilon_{n}^{*} \equiv\left(\frac{l u_{l l}}{u_{l}}-\frac{l u_{c l}}{u_{c}}\right)^{-1}, v_{n} \equiv \frac{p_{y} y_{n}}{\left(1-T^{\prime}\right) n \phi l_{n}}=\left(1-\alpha_{n}\right) \beta$, and $\left.\varepsilon_{y l} \equiv \frac{l_{n}}{y_{n}} \frac{d y_{n}}{d l_{n}}\right|_{\bar{u}}$. The last elasticity can be written as $\varepsilon_{y l}=\frac{\varepsilon_{y t}}{\varepsilon_{l t}}$, where $\varepsilon_{y t}\left(\varepsilon_{l t}\right)$ is the compensated tax elasticity of $y_{n}\left(l_{n}\right)$, since the government uses the marginal tax rate to change $l_{n}$ at a given utility level. Upon substitution for the expressions for the elasticities $\varepsilon_{l t}(10)$, and $\varepsilon_{y t}$ (16), we obtain (45).

The first-order condition for $u_{n}$ is

$$
\begin{aligned}
\frac{\partial \mathcal{H}}{\partial u_{n}}= & \left(\Psi^{\prime}+\left.\lambda\left(n \phi_{x} l_{n}-p_{x}\right) \frac{d x_{n}}{d u_{n}}\right|_{\bar{l}}+\left.\lambda\left(n \phi_{y} l_{n}-p_{y}\right) \frac{d y_{n}}{d u_{n}}\right|_{\bar{l}}-\left.\lambda \frac{d c_{n}}{d u_{n}}\right|_{\bar{l}}\right) f(n() 96) \\
& \left.\theta_{n} \frac{l_{n} u_{l c}}{n} \frac{d c_{n}}{d u_{n}}\right|_{\bar{l}}=\frac{d \theta_{n}}{d n} .
\end{aligned}
$$

(Note that we defined $\theta_{n}$ negatively.) We can simplify this expression using the Envelope Theorem, which implies that $\left.\frac{d x_{n}}{d u_{n}}\right|_{\bar{l}}=\left.\frac{d y_{n}}{d u_{n}}\right|_{\bar{l}}=0$, so that

$$
\frac{\partial \mathcal{H}}{\partial u_{n}}=\left(\Psi^{\prime}-\left.\lambda \frac{d c_{n}}{d u_{n}}\right|_{\bar{l}}\right) f(n)-\left.\theta_{n} \frac{l_{n} u_{l c}}{n} \frac{d c_{n}}{d u_{n}}\right|_{\bar{l}}=-\frac{d \theta_{n}}{d n} .
$$

This is a standard expression (see e.g. Mirrlees (1971)). One cannot solve this differential equation analytically without making additional assumptions on the distribution of abilities or (social) preferences. 


\section{Optimal non-linear education subsidies}

If the government can only freely set education policy and has no access to the non-linear income tax, the government optimizes both $S_{x}$ and $S_{y}$ by controlling $x_{n}$ and $y_{n}$. Further, it must take into account the indirect effects on $l_{n}$ and $c_{n}$. The first-order condition for optimizing social welfare with respect to $x_{n}$ amounts to

$$
\begin{aligned}
\frac{\partial \mathcal{H}}{\partial x_{n}}= & \lambda\left(n \phi_{x} l_{n}-p_{x}+\left.n \phi\left(x_{n}, y_{n}\right) \frac{d l_{n}}{d x_{n}}\right|_{\bar{y}, \bar{u}}-\left.\frac{d c_{n}}{d x_{n}}\right|_{\bar{y}, \bar{u}}\right) f(n)+ \\
& \frac{\theta_{n}}{n}\left(\left.u_{l} \frac{d l_{n}}{d x_{n}}\right|_{\bar{y}, \bar{u}}+\left.l_{n} u_{l l} \frac{d l_{n}}{d x_{n}}\right|_{\bar{y}, \bar{u}}+\left.l_{n} u_{l c} \frac{d c_{n}}{d x_{n}}\right|_{\bar{y}, \bar{u}}\right)=0
\end{aligned}
$$

Substituting $\left.\frac{d c_{n}}{d x_{n}}\right|_{\bar{y}, \bar{u}}=\left.\frac{d c_{n}}{d l_{n}} \frac{d l_{n}}{d x_{n}}\right|_{\bar{y}, \bar{u}}=-\left.\frac{u_{l}}{u_{c}} \frac{d l_{n}}{d x_{n}}\right|_{\bar{y}, \bar{u}}=\left.n \phi(.) \frac{d l_{n}}{d x_{n}}\right|_{\bar{y}, \bar{u}}$ (where the last equality follows from the marginal rate of substitution (37) and $T^{\prime}=0$ ), $u_{l}=-u_{c} n \phi($.$) , and n \phi_{x} l_{n}-p_{x}=-S_{x}^{\prime} p_{x}$ (from the first-order condition for $\left.x_{n}(38)\right)$, we arrive at

$$
\frac{-S_{x}^{\prime}}{1-S_{x}^{\prime}}=\frac{u_{c} \theta_{n} / \lambda}{n f(n)}\left(1+\frac{1}{\varepsilon_{n}^{*}}\right) \frac{\varepsilon_{l x}}{\gamma_{n}},
$$

where $\gamma_{n} \equiv \frac{\left(1-S_{x}^{\prime}\right) p_{x} x_{n}}{n \phi l_{n}}=\alpha_{n} \beta$ and $\left.\varepsilon_{l x} \equiv \frac{x_{n}}{l_{n}} \frac{d l_{n}}{d x_{n}}\right|_{\bar{y}, \bar{u}}$.

The first-order condition for $y_{n}$ is

$$
\begin{aligned}
\frac{\partial \mathcal{H}}{\partial y_{n}}= & \lambda\left(n \phi_{y} l_{n}-p_{y}+\left.n \phi\left(x_{n}, y_{n}\right) \frac{d l_{n}}{d y_{n}}\right|_{\bar{x}, \bar{u}}-\left.\frac{d c_{n}}{d y_{n}}\right|_{\bar{x}, \bar{u}}\right) f(n)+ \\
& \frac{\theta_{n}}{n}\left(\left.u_{l} \frac{d l_{n}}{d y_{n}}\right|_{\bar{x}, \bar{u}}+\left.l u_{l l} \frac{d l_{n}}{d x_{n}}\right|_{\bar{x}, \bar{u}}+\left.l_{n} u_{l c} \frac{d c_{n}}{d x_{n}}\right|_{\bar{x}, \bar{u}}\right)=0 .
\end{aligned}
$$

In a similar way as with the first-order condition for $x_{n}$, we write this expression as

$$
\frac{-S_{y}^{\prime}}{1-S_{y}^{\prime}}=\frac{u_{c} \theta_{n} / \lambda}{n f(n)}\left(1+\frac{1}{\varepsilon_{n}^{*}}\right) \frac{\varepsilon_{l y}}{v_{n}},
$$

where $v_{n} \equiv \frac{\left(1-S_{y}^{\prime}\right) p_{y} y_{n}}{n \phi l_{n}}=\left(1-\alpha_{n}\right) \beta$ and $\left.\varepsilon_{l y} \equiv \frac{y_{n}}{l_{n}} \frac{d l_{n}}{d y_{n}}\right|_{\bar{y}, \bar{u}}$. 
Using the first-order conditions for $x_{n}$ and $y_{n}$ (i.e., (99) and (101)), we find

$$
\frac{-S_{x}^{\prime}}{1-S_{x}^{\prime}} \frac{\gamma_{n}}{\varepsilon_{l x}}=\frac{-S_{y}^{\prime}}{1-S_{y}^{\prime}} \frac{v_{n}}{\varepsilon_{l y}} .
$$

We can rewrite this expression by substituting the corresponding expressions for $\varepsilon_{l x}$ and $\varepsilon_{l y}$. We find $\varepsilon_{l x}$ by setting $\tilde{s}_{x}$ and $\tilde{s}_{y}$ such that $\tilde{y}_{n}=0$ (note that in the first-order condition for $x_{n}, y_{n}$ is constant, so that $\tilde{y}_{n}=0$ ). This implies that

$$
\varepsilon_{y s_{x}} \tilde{s}_{x}+\varepsilon_{y s_{y}} \tilde{s}_{y}=0 .
$$

Solving $\tilde{s}_{y}$ in terms of $\tilde{s}_{x}$ and substituting this in the expressions for $\tilde{l}_{n}=$ $\varepsilon_{l s_{x}} \tilde{s}_{x}+\varepsilon_{l s_{y}} \tilde{s}_{y}$ and $\tilde{x}_{n}=\varepsilon_{x s_{x}} \tilde{s}_{x}+\varepsilon_{x s_{y}} \tilde{s}_{y}$ we find

$$
\varepsilon_{l x}=\frac{\tilde{l}_{n}}{\tilde{x}_{n}}=\frac{\varepsilon_{l s_{x}}-\varepsilon_{l s_{y}} \frac{\varepsilon_{y s_{x}}}{\varepsilon_{y s_{y}}}}{\varepsilon_{x s_{x}}-\varepsilon_{x s_{y}} \frac{\varepsilon_{y s_{x}}}{\varepsilon_{y s_{y}}}}=\frac{\varepsilon_{l s_{x}} \varepsilon_{y s_{y}}-\varepsilon_{l s_{y}} \varepsilon_{y s_{x}}}{\varepsilon_{x s_{x}} \varepsilon_{y s_{y}}-\varepsilon_{x s_{y}} \varepsilon_{y s_{x}}} .
$$

In a similar way, we find for $\varepsilon_{l y}$ (using that $\tilde{x}_{n}=0$ in the first-order condition for $y_{n}$ )

$$
\varepsilon_{l y}=\frac{\tilde{l}_{n}}{\tilde{y}_{n}}=\frac{\varepsilon_{l s_{x}}-\varepsilon_{l s_{y}} \frac{\varepsilon_{x s_{x}}}{\varepsilon_{x x y}}}{\varepsilon_{y s_{x}}-\varepsilon_{y s_{y}} \frac{\varepsilon_{x s_{x}}}{\varepsilon_{x s_{y}}}}=\frac{\varepsilon_{l s_{y}} \varepsilon_{x s_{x}}-\varepsilon_{l s_{x}} \varepsilon_{x s_{y}}}{\varepsilon_{x s_{x}} \varepsilon_{y s_{y}}-\varepsilon_{x s_{y}} \varepsilon_{y s_{x}}} .
$$

Substituting (104) and (105) into (102), we find the expression

$$
\frac{-S_{x}^{\prime}}{1-S_{x}^{\prime}} \gamma_{n}\left(\varepsilon_{x s_{x}}-\frac{\varepsilon_{l s_{x}}}{\varepsilon_{l s_{y}}} \varepsilon_{x s_{y}}\right)=\frac{-S_{y}^{\prime}}{1-S_{y}^{\prime}} v_{n}\left(\frac{\varepsilon_{l s_{x}}}{\varepsilon_{l s_{y}}} \varepsilon_{y s_{y}}-\varepsilon_{y s_{x}}\right) \text {. }
$$

Moreover, we can use the elasticities at the end of sub-section 3.1 (i.e., (11) and (12)) to eliminate $\varepsilon_{l s_{x}}$ and $\varepsilon_{l s_{y}}$ to arrive at

$$
\frac{-S_{x}^{\prime}}{1-S_{x}^{\prime}}\left(\varepsilon_{x s_{x}}-\frac{\gamma_{n}}{v_{n}} \varepsilon_{x s_{y}}\right)=\frac{-S_{y}^{\prime}}{1-S_{y}^{\prime}}\left(\varepsilon_{y s_{y}}-\frac{v_{n}}{\gamma_{n}} \varepsilon_{y s_{x}}\right) .
$$

This can be simplified using the definitions for the elasticities as

$$
S_{x}^{\prime}=S_{y}^{\prime} .
$$

The optimal level of the education tax follows from substitution of the relevant elasticities in the first-order condition for $x_{n}$ (99). In particular, we can substitute the elasticities at the end of sub-section 3.1 in $\varepsilon_{l x}=\frac{\varepsilon_{l_{x}} \varepsilon_{y s_{y}}-\varepsilon_{s_{y}} \varepsilon_{y s_{x}}}{\varepsilon_{x s_{x}} \varepsilon_{y s_{y}}-\varepsilon_{x s_{y}} \varepsilon_{y s_{x}}}$ $=\gamma_{n} \varepsilon_{n}$ and use (108) in (99), to arrive at (46). 


\section{Optimal non-linear income taxation and non-linear ed- ucation subsidies}

If the government optimizes all its instruments, it employs the control variables $l_{n}, x_{n}$, and $y_{n}$ to optimize social welfare, taking into account the indirect effects on $c_{n}$. This yields the following first-order conditions for $x_{n}$ and $y_{n}$

$$
\begin{aligned}
\frac{\partial \mathcal{H}}{\partial x_{n}} & =\lambda\left(n \phi_{x} l_{n}-p_{x}-\left.\frac{d c_{n}}{d x_{n}}\right|_{\bar{u}, \bar{l}, \bar{y}}\right) f(n)=0, \\
\frac{\partial \mathcal{H}}{\partial y_{n}} & =\lambda\left(n \phi_{y} l_{n}-p_{y}-\left.\frac{d c_{n}}{d y_{n}}\right|_{\bar{u}, \bar{l}, \bar{x}}\right) f(n)=0 .
\end{aligned}
$$

For the indirect impacts on consumption, we find $\left.\frac{d c_{n}}{d x_{n}}\right|_{\bar{u}, \bar{l}, \bar{y}}=\left.\frac{d c_{n}}{d y_{n}}\right|_{\bar{u}, \bar{l}, \bar{x}}=0$ by differentiating the household budget constraint (36) and substituting the individuals' first-order conditions for $x_{n}$ and $y_{n}$ (38) and (39). Using these results in (109) and (110), we find (47) and (48).

The first-order condition for $l_{n}$ is given by

$$
\frac{\partial \mathcal{H}}{\partial l_{n}}=\lambda\left(n \phi\left(x_{n}, y_{n}\right)-\left.\frac{d c_{n}}{d l_{n}}\right|_{\bar{u}, \bar{x}, \bar{y}}\right) f(n)+\frac{\theta_{n}}{n}\left(u_{l}+l_{n} u_{l l}+\left.l_{n} u_{l c} \frac{d c_{n}}{d l_{n}}\right|_{\bar{u}, \bar{x}, \bar{y}}\right)=0
$$

where we substitute $\left.\frac{d c_{n}}{d l_{n}}\right|_{\bar{u}, \bar{x}, \bar{y}}=\left(1-T^{\prime}\right) n \phi\left(x_{n}, y_{n}\right)$ (found by taking the total derivative of utility $u\left(c_{n}, l_{n}\right)$ and substituting the marginal rate of substitution (37) to eliminate $\left.u_{l}\right)$, and $\left.u_{l}=u_{c}\left(1-T^{\prime}\right)\right) n \phi\left(x_{n}, y_{n}\right)$ (found from (37)) to arrive at (51).

\section{Optimal non-linear income taxation and imperfect non- linear education subsidies}

If the government can only optimize $T$ and $S_{x}$, it uses $l_{n}$ and $x_{n}$ as control variables, taking into account the indirect effects of changing $l_{n}$ and $x_{n}$ on $c_{n}$ and $y_{n}$. The first-order condition for social-welfare maximization with 
respect to $x_{n}$ is given by

$$
\begin{aligned}
\frac{\partial \mathcal{H}}{\partial x_{n}}= & \lambda\left(n \phi_{x} l_{n}-p_{x}-\left.\frac{d c_{n}}{d x_{n}}\right|_{\bar{u}, \bar{l}}-\left.\left(n \phi_{y} l_{n}-p_{y}\right) \frac{d y_{n}}{d x_{n}}\right|_{\bar{u}, \bar{l}}\right) f(n)+(11] \\
& \frac{\theta_{n}}{n}\left(\left.u_{l} \frac{d l_{n}}{d x_{n}}\right|_{\bar{u}, \bar{l}}+\left.l_{n} u_{l l} \frac{d l_{n}}{d x_{n}}\right|_{\bar{u}, \bar{l}}+\left.l_{n} u_{l c} \frac{d c_{n}}{d x_{n}}\right|_{\bar{u}, \bar{l}}\right)=0
\end{aligned}
$$

Substituting $n \phi_{x} l_{n}-p_{x}=-S_{x}^{\prime} p_{x},\left.\frac{d c_{n}}{d x_{n}}\right|_{\bar{u}, \bar{l}}=0$ (found by differentiating the household budget constraint (36) and substituting the individuals' first-order condition for $\left.x_{n}(38)\right),\left(n \phi_{y} l_{n}-p_{y}\right)=\frac{T^{\prime} p_{y}}{1-T^{\prime}}$, and $\left.\frac{d l_{n}}{d x_{n}}\right|_{\bar{u}, \bar{l}}=0$ (by definition), we find

$$
\frac{-S_{x}^{\prime}}{\left(1-S_{x}^{\prime}\right)\left(1-T^{\prime}\right)} p_{x} x_{n}\left(1-S_{x}^{\prime}\right)\left(1-T^{\prime}\right)+\frac{T^{\prime}}{1-T^{\prime}} p_{y} y_{n} \varepsilon_{y x}=0
$$

where $\left.\varepsilon_{y x} \equiv \frac{x_{n}}{y_{n}} \frac{d y_{n}}{d x_{n}}\right|_{\bar{u}, \vec{l}}$. By using $v_{n} \equiv \frac{p_{y} y_{n}}{\left(1-T^{\prime}\right) n \phi l_{n}}=\left(1-\alpha_{n}\right) \beta$ and $\gamma_{n} \equiv$ $\frac{\left(1-S_{x}^{\prime}\right) p_{x} x_{n}}{n \phi l_{n}}=\alpha_{n} \beta$, we can write this expression as

$$
\frac{S_{x}^{\prime}}{\left(1-S_{x}^{\prime}\right)\left(1-T^{\prime}\right)} \gamma_{n}=\frac{T^{\prime}}{1-T^{\prime}} v_{n} \varepsilon_{y x}
$$

We find $\varepsilon_{y x}$ by defining $\tilde{s}_{x}$ and $\tilde{t}$ such that $\tilde{l}=0$ :

$$
\varepsilon_{l s_{x}} \tilde{s}_{x}+\varepsilon_{l t} \tilde{t}=0
$$

Solving $\tilde{t}$ in terms of $\tilde{s}_{x}$ and substituting this in the expressions for $\tilde{y}_{n}=$ $\varepsilon_{y s_{x}} \tilde{s}_{x}+\varepsilon_{y t} \tilde{t}$ and $\tilde{x}_{n}=\varepsilon_{x s_{x}} \tilde{s}_{x}+\varepsilon_{x t} \tilde{t}$, we find

$$
\varepsilon_{y x}=\frac{\tilde{y}_{n}}{\tilde{x}_{n}}=\frac{\varepsilon_{y s_{x}}-\varepsilon_{y t} \frac{\varepsilon_{l s x}}{\varepsilon_{l t}}}{\varepsilon_{x s_{x}}-\varepsilon_{x t} \frac{\varepsilon_{l s x}}{\varepsilon_{l t}}} .
$$

We can substitute the elasticities at the end of sub-section 3.1 to find

$$
\varepsilon_{y x}=\frac{\left(1-\sigma_{n}\right) \alpha_{n}}{1-\left(1-\alpha_{n}\right)\left(1-\sigma_{n}\right)} .
$$

Substituting the last result into (114), and using $\gamma_{n}=\alpha_{n} \beta$ and $v_{n}=(1-$ $\left.\alpha_{n}\right) \beta$, we arrive at (52). 
The first-order condition optimizing the Hamiltonian (43) with respect to $l_{n}$ is

$$
\begin{aligned}
\frac{\partial \mathcal{H}}{\partial l_{n}}= & \lambda\left(n \phi\left(x_{n}, y_{n}\right)-\left.\frac{d c_{n}}{d l_{n}}\right|_{\bar{u}, \bar{x}}+\left.\left(n \phi_{y} l_{n}-p_{y}\right) \frac{d y_{n}}{d l_{n}}\right|_{\bar{u}, \bar{x}}\right) f(n)+(118 \\
& \frac{\theta_{n}}{n}\left(u_{l}+l_{n} u_{l l}+\left.l_{n} u_{l c} \frac{d c_{n}}{d l_{n}}\right|_{\bar{u}, \bar{x}}\right)=0
\end{aligned}
$$

Substituting $\left.\frac{d c_{n}}{d l_{n}}\right|_{\bar{u}, \bar{x}}=-\frac{u_{l}}{u_{c}}=\left(1-T^{\prime}\right) n \phi($.$) (derived by differentiating$ utility $u\left(c_{n}, l_{n}\right)$ and substituting the marginal rate of substitution (37)), $\left(n \phi_{y} l_{n}-p_{y}\right)=\frac{T^{\prime} p_{y}}{1-T^{\prime}}$ (derived from the individuals' first-order conditions for $y_{n}(39)$ and $S_{y}=0$ ), and $u_{l}=-u_{c}\left(1-T^{\prime}\right) n \phi($.$) (derived from (37)), we find$

$$
\frac{T^{\prime}}{1-T^{\prime}}=\frac{u_{c} \theta_{n} / \lambda}{n f(n)}\left(1+\frac{1}{\varepsilon_{n}^{*}}\right)\left(\frac{1}{1+v \varepsilon_{y l}}\right),
$$

where $v_{n} \equiv \frac{p_{y} y_{n}}{\left(1-T^{\prime}\right) n \phi l_{n}}$ and $\left.\varepsilon_{y l} \equiv \frac{l_{n}}{y_{n}} \frac{d y_{n}}{d l_{n}}\right|_{\bar{u}, \bar{x}}$.

We find $\varepsilon_{y l}$ by defining $\tilde{s}_{x}$ and $\tilde{t}$ such that $\tilde{x}=0$ :

$$
\varepsilon_{x s_{x}} \tilde{s}_{x}+\varepsilon_{x t} \tilde{t}=0 .
$$

Solving $\tilde{t}$ in terms of $\tilde{s}_{x}$ and substituting this in the expressions for $\tilde{y}_{n}=$ $\varepsilon_{y s_{x}} \tilde{s}_{x}+\varepsilon_{y t} \tilde{t}$ and $\tilde{l}_{n}=\varepsilon_{l s_{x}} \tilde{s}_{x}+\varepsilon_{l t} \tilde{t}$, we obtain

$$
\varepsilon_{y l}=\frac{\tilde{y}_{n}}{\tilde{l}_{n}}=\frac{\varepsilon_{y s_{x}}-\varepsilon_{y t} \frac{\varepsilon_{x s_{x}}}{\varepsilon_{x t}}}{\varepsilon_{l s_{x}}-\varepsilon_{l t} \frac{\varepsilon_{x s_{x}}}{\varepsilon_{x t}}} .
$$

Substituting the elasticities from the end of sub-section (3.1), we arrive at

$$
\varepsilon_{y l}=\frac{1+\varepsilon_{n}}{\varepsilon_{n}} \frac{\sigma_{n}}{\left(1-\alpha_{n}\right) \sigma_{n}+\alpha_{n}} .
$$

Substitution of this last result into (119) yields (53). 